
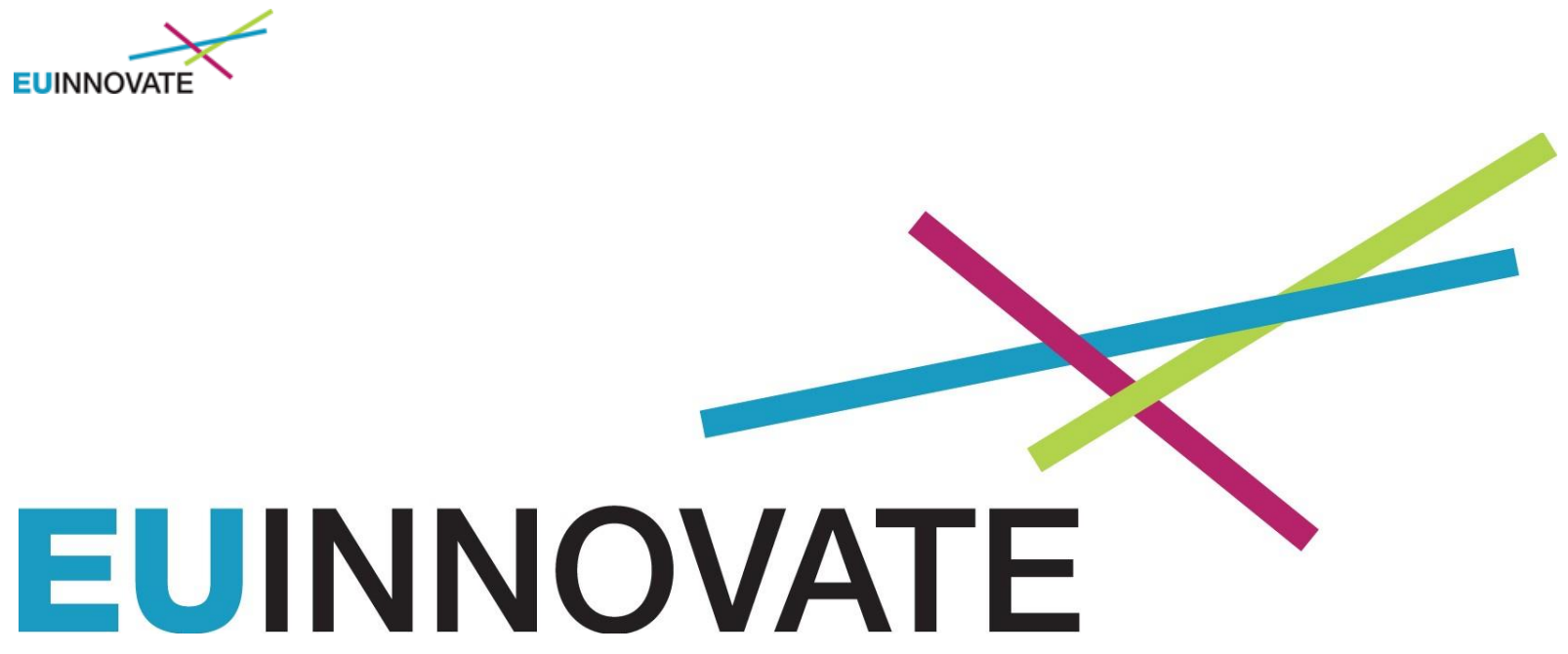

Deliverable D6.5 - Part 1

Publishable manuscript on ex ante policy testing of novel policy instruments

Project name: $\quad$ Sustainable Lifestyles 2.0: End User Integration, Innovation and Entrepreneurship

Grant agreement no: $\quad 613194$

Number of deliverable: $\quad$ D6.5

Authors:

Rosina Watson, Kristian Roed Nielsen, Christine Mera, Hugh N. Wilson, Emma K. Macdonald, Lucia Reisch, Stefan Hemel

Name of peer-review: Frank Belz, Reinhard von Wittken

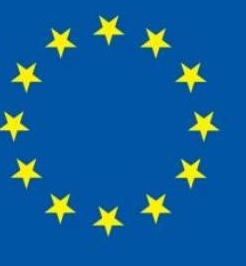


Watson R.J., Nielsen K.R., Mera,C, Wilson H.N., Macdonald E.K., Reisch L., Hemel S., Policy for sustainable entrepreneurship: A crowdsourced framework, D6.5 Part 1, 2016.

EUINNOVATE

D6.5: POLICY FOR SUSTAINABLE

ENTREPRENEURSHIP: A CROWDSOURCED

\section{FRAMEWORK}

\section{INTRODUCTION TO DELIVERABLE 6.5 - PART 1}

The objectives of the final stages of Work Package 6 were to :

- Suggest novel elements of a comprehensive EU policy to support company-driven sustainability innovation, and sustainability entrepreneurship

- Test this empirically by means of experiments as well as in a social media enabled conference

This deliverable reports on the testing the novel policy elements developed in the earlier stages of the Work Package. Our approach to this task was two pronged. First, we sought to test a broad range of proposed policy approaches by means of a social media conference (which we called The Sustainability Innovation Exchange). The findings from this research are presented in the manuscript which follow which will shortly be submitted for publication in the journal Research Policy. This Part 1 of Deliverable 6.5 provides policymakers with a practical framework, co-created with sustainable entrepreneurs and other individuals interested in sustainable entrepreneurship, which lays out five key policy domains within which policy can be used to encourage sustainable entrepreneurship, and recommends policy measures within each domain.

\section{POLICY FOR SUSTAINABLE ENTREPRENEURSHIP: A CROWDSOURCED}

\section{FRAMEWORK}

This paper proposes a framework which is intended to be used in practice to stimulate systematic thinking on how policy can encourage sustainable entrepreneurship. This framework has indeed begun to be applied in practice, by the authors in consultation with the Academy of Business in Society (ABIS), in the context of the EU. Table 5 shows ten specific EU-level policy recommendations which were derived from the framework and shared with EU policymakers and other interested stakeholders at an EU Policy Roundtable, and at the EU-Innovate Final Conference. The framework could similarly be used as a policy development tool within a specific industry context, or with governments at a national, regional or local level.

This paper also offers policymakers a practical example of how policy can be crowdsourced from a diverse group of stakeholders, and outlines a step-by-step method for running a similar policy innovation process.

This is the Author Accepted M anuscript issued with:

Creative Commons Attribution Non-Commercial License (CC:BY:NC: 3.0).

Please refer to any applicable publisher terms of use. 


\title{
POLICY FOR SUSTAINABLE ENTREPRENEURSHIP: A CROWDSOURCED FRAMEWORK
}

\author{
Rosina Watson*, Kristian Roed Nielsen**, Christine Mera*, Hugh N. Wilson*, Emma K. \\ Macdonald*, Lucia Reisch** and Stefan Hemel* \\ *Cranfield School of Management, UK **Copenhagen Business School
}

\begin{abstract}
Sustainable entrepreneurship - entrepreneurship with social and ecological gains as well as economic ones-has the potential to play a significant role in addressing societal and environmental challenges. However, sustainability and entrepreneurship have hitherto been addressed through separate policy regimes, and it is not clear how policymakers can encourage sustainable entrepreneurship specifically. The authors develop a policy framework for sustainable entrepreneurship, using an open innovation approach with policymakers, business executives, academics, entrepreneurs and other relevant actors, including an online crowdsourcing event with 150 participants. The framework incorporates five policy domains: creating awareness and skills; building networks; funding and investing; measuring impact and performance; and innovating government. The article proposes a modified version of the multilevel perspective (MLP) on how socio-technical transitions occur, since the findings suggest that policy can catalyse the facilitation and aggregation of innovations coming from the niche level, thereby evolving the socio-technical regime, in addition to the role of policy described in earlier work in stabilising the socio-technical regime. Contributions to entrepreneurship policy literature include the policy domain of measuring impact and performance, as appropriate success measures are non-trivial in a triple bottom line environment, and the potential for open policy innovation in entrepreneurship policy. Contributions to sustainability policy literature include the requirements for support mechanisms and capacity building to empower individuals to contribute as innovators and entrepreneurs and not just consumers. The sustainable entrepreneurship framework can be applied by policymakers to develop context-specific policies: this is illustrated with a worked example of EU policy recommendations. The paper also outlines a method for crowdsourcing policy innovations.
\end{abstract}

\section{NOTE:}

This project received funding from the European Union's Seventh Framework Programme for research, technological development and demonstration under grant agreement no 613194, as part of the EU-InnovatE project. In accordance with the project's Description of Work, this Deliverable 6.5 is in the form of a publishable manuscript which will shortly be submitted for consideration for publication by the journal Research Policy. The recommendations summarized in this manuscript were presented at a Round Table meeting with EU policymakers in Brussels on $6^{\text {th }}$ October 2016 and at the EU Final Conference in Brussels on $22^{\text {nd }}$ November 2016. 
Highlights from the crowdsourcing event were also shared with participants in the form of a highlights report.

Acknowledgements: This project would not have been possible without the support and cooperation of many partner organizations and colleagues who share the authors' passion for finding ways to build a more sustainable society. We extend our thanks to our colleagues at TUM, particularly Frank Belz, Julia Binder, Henrike Purtik and Reinhard von Wittken, for their excellent academic leadership and coordination of the overall EU-InnovatE project of which this paper forms a part, and to the many other consortium members who participated in the many research events involved in the delivery of this work.

We are very grateful to Abbie Curtis, Caroline Holme, Chris Coulter, Alex Lewis and Christine de Groot at GlobeScan who made the Sustainability Innovation Exchange possible, and supported us with their professional knowledge and experience in running online stakeholder crowdsourcing events, as well as offering moral support and encouragement throughout the challenges presented by setting up and running such an event. We really could not have done it without you.

We would also like to acknowledge the valuable support we received from faculty members at Cranfield University who gave up their time to moderate the online discussions, as well as helping to recruit participants - David Grayson, Palie Smart, Ruth Bender and Stephanie Hussels. They did a fantastic job in an unfamiliar medium and helped to make the event engaging and fast paced. We would also like to thank all the guest contributors who generously dedicated their time and insights to the event. Particular thanks to Liz Varga and to Guy Champniss for his timely introduction to GlobeScan. Thank you to our Cranfield colleagues Lina Del Grosso, Hannah Park, Jo Wood, Katherine Lakeland, Dawn Richardson, Greg Boulter, David Medcalf, Toby Thompson and Chris Ripley for their help in preparing content for the event and recruiting participants. Your positive 'can do' attitude was really appreciated. Also thanks to all those at Cranfield and CBS and the other EU-InnovatE partner universities who used their social networks to help publicise the event.

Thank you too to our colleagues James Goodman, Gemma Adams, Louise Armstrong and Corina Angheloiu at Forum for the Future for their intellectual input and unfailing enthusiasm, and particularly for running a vibrant pre-study face-to-face citizen innovation workshop in London in February 2016. Last, but by no means least, our gratitude goes to our colleagues Simon Pickard, Marco Matrisciano, Patrick Nieman and Ludwig Roger at the Academy of Business in Society. They were instrumental in developing our framework into specific recommendations for EU policymakers, and organized the key validation events at which we shared our findings. They kept this research close to the reality of policymaking in the EU, and helped to make it relevant to practice.

It was a pleasure to work with all of you, and to feel part of such a collaborative team effort. We hope you will agree that we had a lot of fun along the journey. We hope you will be proud of the output, and that the ripples from this work will continue to drive positive change in the coming years. 


\section{INTRODUCTION}

Sustainable entrepreneurship has the potential to play a significant role in addressing environmental and social issues, and in working towards a more sustainable future for our planet (Hockerts and Wüstenhagen, 2010). Following Belz and Binder (2015, p2), we define sustainable entrepreneurship as "the recognition, development and exploitation of opportunities by individuals to bring into existence future goods and services with economic, social and ecological gains." While entrepreneurs typically focus on delivering economic returns, sustainable entrepreneurs balance social and environmental goals alongside economic criteria (Belz and Binder, 2015).

However, there is an absence of policy specifically targeted at encouraging sustainable entrepreneurship. Sustainability and innovation have historically been addressed through separate policy regimes (Foxon and Pearson, 2008). Sustainability policy typically focuses on the behaviour of large corporates (Taylor et al., 2013b), or on the consumption behaviour of individual consumers (Ölander and Thøgersen, 1995). Innovation policy similarly focuses on encouraging R\&D by incumbent firms with little or no emphasis on sustainability (Henkel and von Hippel, 2005; von Hippel, 2005), and on encouraging startups for economic reasons, again with little specific attention given to sustainability (Audretsch and Link, 2012). There is therefore a need to recognise and encourage the role in sustainable innovation of individual actors (Nielsen et al., 2016; Seyfang and Smith, 2007), and in particular, sustainable entrepreneurs. The extant sustainable entrepreneurship literature offers few insights into how policy can encourage this phenomenon. Entrepreneurship policy literature discusses how governments can encourage entrepreneurial opportunity and activity in general (Audretsch and Link, 2012), but does not identify which interventions should be prioritised to drive sustainable entrepreneurship in particular. This research therefore bridges what we term a 'triple policy disconnect' between sustainability, innovation and entrepreneurship by setting out a framework for how policy can foster sustainable entrepreneurship. We define policy as "all forms of social control, including those that harness wider social forces beyond government, including the influence of business and other actors in society" (Taylor et al., 2013, p. 489, after Gunningham and Sinclair, 1999).

This framework for sustainable entrepreneurship policy was derived through a series of consultation activities, culminating in a one-day online crowdsourcing event, with over 200 
individuals with an interest in sustainable entrepreneurship who identified with nine different actor roles including entrepreneur, policymaker, academic, investor and thought leader. Crowdsourcing is an open innovation (Chesbrough, 2012) technique defined as "a type of participative online activity in which an individual, organization, or company ... proposes for a group of individuals of varying knowledge, heterogeneity, and number, via a flexible open call, the voluntary undertaking of a task" (Estelles Arolas and González-Ladrón-De-Guevara, 2012, p. 11). Crowdsourcing is increasingly being used an open innovation tool within the public sector (Aitamurto, 2012; Lee et al., 2012; Mergel and Desouza, 2013), particularly in relation to sustainability issues for which a large and diverse range of stakeholders is often necessary to envision and support potential solutions, and a complex mix of policy strategies and instruments is required to implement these solutions successfully (Persson, 2006). This technique was therefore applicable to our research question, and aligned with our premise that individual actors have a potentially significant role in innovating towards system level changes.

Through inductive analysis of almost 1,700 text comments posted during the online crowdsourcing event, we develop a framework (Figure 1) which sets out the five main policy domains within which sustainable entrepreneurship can be encouraged. We report on how these policy domains address the motivations, abilities and opportunities (Ölander and Thøgersen, 1995) of sustainable entrepreneurs, describe the focus of the policies in each domain, and illustrate these policy areas with policy examples suggested by our participants.

Our findings offer a new perspective on the types of entrepreneurship policy levers which are more salient for sustainable entrepreneurs, and suggest how sustainability policy could be extended to include policies which foster sustainable entrepreneurship. We thereby contribute to the sustainable entrepreneurship, sustainability policy and entrepreneurship policy literatures with an emerging framework for designing and implementing policy interventions to support sustainable entrepreneurship. We also contribute to the literature which uses the multi-level perspective (MLP) to explore sustainable transitions (Geels, 2002; Geels and Schot, 2007) by conceiving policy not just as a stabilising force within an existing socio-technical regime, but also as a catalyst for change which can accelerate and aggregate niche-level innovations (see Figure 3).

The paper proceeds as follows: We expand on our conception of sustainable entrepreneurship, and on the current disconnects in policy regimes relating to environmental 
sustainability, innovation and entrepreneurship. We then show how the multi-level perspective (MLP) provides a theoretical basis for articulating the linkages between them. We detail our multi-stage data collection approach before presenting the policy framework emerging from our analysis of crowdsourced insights. Finally, we discuss theoretical contributions to the entrepreneurship and sustainability policy literatures as well as offering practical insights into how to conduct research using crowdsourcing.

\section{BACKGROUND}

\subsection{The triple disconnect: Sustainability, innovation and entrepreneurship policy}

Sustainability policy literature does not typically focus on individual entrepreneurship activities, or indeed on innovation activities in general, but on changing the behaviour of large corporates (Taylor et al., 2013b), or on the consumption behaviour of consumers (Ölander and Thøgersen, 1995). However, the range of potential policy instruments that appears in this literature extends beyond regulation and financial incentives to information-based approaches and support and capacity building measures (Gouldson et al., 2008; Taylor et al., 2013b). The adoption of alternative tools is increasingly considered due to the recognition of "influences of other drivers of individual behaviour beyond the financial and economic" (Taylor et al., 2012, p. 286). Despite policymakers' acknowledgement that the effectiveness of policy and regulation is affected by a wide range of social and political forces (Taylor et al., 2013b), the role of the individual actor is still commonly limited to that of a relatively passive consumer (see for example Taylor et al., 2013a, p. 492) whose primary roles are to "choose products" and "monitor performance" (of companies).

Innovation policy literature similarly has traditionally focused on encouraging research and development by incumbent firms, whether large corporates or SMEs (Henkel and von Hippel, 2005; von Hippel, 2005). A stream of research on social innovation (Chalmers, 2012; Lettice and Parekh, 2010; Martins and Bermejo, 2015; Mont et al., 2014) recognises that "innovation is not just an economic mechanism or a technical process. It is above all a social phenomenon" (European Commission, Green Paper on Innovation, 1996). Innovation therefore requires a co-evolution between the collective actions of individuals and their structural context (Cajaiba-Santana, 2014). However, this literature does not go as far as developing a policy 
framework to support this co-evolution between individual actors and the policy environment in which they operate.

There is therefore a need to not only to stimulate the development of a sustainable innovation policy regime, bringing innovation and sustainability policy regimes together, but also to consider the individual as an active innovator and solution provider (either alone or in working with others) in the design of policy to encourage sustainable innovation (Foxon and Pearson, 2008; Seyfang and Smith, 2007).

Entrepreneurship policy literature centres on the role of the individual innovator, and defines the purpose of policy as "to encourage agents of change, or entrepreneurs, to innovate" (Audretsch and Link, 2012, p. 14). Entrepreneurship policy embraces "a broad spectrum of institutions, agencies and different constituency groups" (Audretsch, Grilo and Thurick, 2007, p. 2) and spans all facets of society, not just economic policy. This literature provides a useful starting point from which to build an understanding of how policy can harness the innovative power of individuals; however, the need remains to examine how - if at all - this entrepreneurship policy literature can be applied when policymakers pursue social and environmental goals.

This paper therefore seeks to connect the environmental policy, innovation policy and entrepreneurship policy domains by examining how policy can specifically foster sustainable entrepreneurship. As previously stated, we conceptualise policy as incorporating "all forms of social control, including those that harness wider social forces beyond government, including the influence of business and other actors in society" (Taylor et al., 2013b, p. 489) and therefore policymakers not just as enforcers but as "initiators, partners and facilitators" (Gouldson et al., 2008, p. 360).

\subsection{Towards connection: A multi-level perspective on sustainable entrepreneurship policy}

As we conceptualise sustainable entrepreneurship as an individual-led phenomenon whilst policy development and implementation is generally conceived of as a top down, institutional-led phenomenon, we use the multi-level perspective (MLP) as a theoretical tool to integrate these perspectives. The MLP is a mid-range theory which conceptualizes the process of sociotechnical transitions (Geels, 2011), including transitions towards sustainability (Verbong \& Geels 2007; Nykvist \& Whitmarsh 2008; Elzen et al. 2011). The theory conceives niche innovation actors - such as sustainable entrepreneurs - as agents of radical innovation who drive 
socio-technical transitions (Geels 2010; 2011); it is therefore highly relevant to the aims of our paper, which explores how policy can enable more sustainable entrepreneurship with the goal of bringing about the transition to a more sustainable future for Europe.

Socio-technical transitions require not only technological changes, but also changes in other practices that typically lock-in systemic change including, for example, user and industrial practices, regulation, infrastructure and symbolic meanings (Geels, 2002; Unruh, 2000). The MLP theory conceptualizes a nested hierarchy of structuring processes consisting of niches, regimes and landscapes as illustrated in Figure 3, left hand panel.

The landscape provides a macro-level structuring context (Rip and Kemp, 1998; Smith et al., 2010) for both the regimes and niches. The landscape "highlights not only the technical and material backdrop that sustains society, but also includes demographical trends, political ideologies, societal values, and macro-economic patterns" (Geels, 2011 p28). It provides "gradients and affordances for how to go about establishing socio-technical configurations that serve societal needs" (Smith et al., 2010, p441). This relationship is however not one way, as the rise of certain regimes can also influence landscape development, for example telecommunication and increasingly fast mobility regimes have driven significant changes at the landscape level in the form of globalization (Smith et al., 2010).

The regime represents the dynamically stable mainstream in which social functions are realised resulting in a 'deep structure' that accounts for the stability of the given socio-technical system (Geels, 2004). Changes within the regime tend to be incremental and path dependent exerting pressures also upon novel alternatives. For example, the development of electric windmills in Denmark was stifled early on because they could not be connected to the electrical grid (Garuda and Karnøe, 2003). The stability of a regime occurs because of the locked-in nature of multiple ongoing processes within science, technology, politics, markets, user preferences and cultural meanings.

The niche is represented by small networks of actors, such as entrepreneurs and start-ups that support innovation on the basis of expectations and visions. Niche actors ultimately hope "that their promising novelties are eventually used in the regime or even replace it" (Geels, 2011 p27), but as their innovations challenge the existing regime and because of the many lock-ins inherent within the regime level, or because the niche innovation may be mismatched with existing regime dimensions, they exist in a precarious state. For example, community energy 
production often faces issues with both legal and infrastructure-based restriction when it comes to power production (Blanchet, 2015).

Each of these levels in the hierarchy link up and reinforce each other, so the process of socio-technical transitions is therefore not causal, and there is no one cause or driver, rather, transitions emerge from multiple dimensions at different levels (Geels, 2011). However, it is argued that these transitions often follow a similar dynamic process: (i.) niche-innovations gather internal momentum (ii.) changes in landscape create pressures on the regime, and if (iii.) there are certain destabilisations within the regime, this creates windows of opportunity for nicheinnovations. MLP theory contends that the socio-technical regime generally acts to lock-in sociotechnical changes, while the niche-level actors act as key sources of radical innovation that challenge the current socio-technical regime. Encouraging these niche players to continually challenge the established regime with new ways of working and living offers great potential to create the kind of societal and economic change envisaged by the EU's FP7 sustainable lifestyles directive. This paper focuses on how regime-level policy may be employed in order to foster more niche-innovation, specifically by sustainable entrepreneurs.

Within the MLP framework, policy at the regime-level is usually assumed to act as a barrier rather than an enabler of more niche innovation, as it usually serves to maintain current socio-technical arrangements and therefore established practices. However, we argue that while policy forms a part of the established socio-technical regime, it also has the potential, if carefully designed and implemented, to facilitate and aggregate innovations at the niche level which in turn challenge and evolve the social-technical regime.

This study builds on the assumption that policies designed and implemented in collaboration with multiple affected stakeholders may be more effective as evidenced by previous findings that "government can solve problems faster and [more] accurately by harnessing a collaborative network of citizen experts" (Lee et al. 2012, p. 150), particularly in relation to environmental issues (Konisky and Beierle, 2001; Koontz, 2006). We conducted a series of consultation activities with over 200 current and potential sustainable entrepreneurs alongside the individuals who support them, including policymakers, consultants, educators and investors, to crowdsource knowledge on how policy can be used to enable sustainable entrepreneurship. Policymakers were consulted as individual actors, recognising that 
government not only influences as an institution, but also through the individual agency of policymakers (Koontz, 2006). Our method is discussed in more detail in the next section.

\section{METHOD}

When public policy seeks to address complex sustainability issues, the participation of multiple actors representing a diverse range of stakeholders may be required in order to envision and support potential solutions. Furthermore, implementation of sustainability policies typically requires a complex mix of policy strategies and instruments (Persson, 2006). Given the diversity of actors required for sustainability policy development, this study adopts a crowdsourcing approach to policy generation. As previously defined, crowdsourcing is "a type of participative online activity in which an individual, organization, or company ... proposes for a group of individuals of varying knowledge, heterogeneity, and number, via a flexible open call, the voluntary undertaking of a task" (Estelles-Arolas and Gonzales-Ladron-de-Guevara, 2012, p. 11). Crowdsourcing is often used in open innovation where it has been found that ideas generated from users are objectively better than those developed by R\&D professionals (Poetz and Schreier, 2012).

West et al., (2014) call for more researchers to use open innovation methods, such as crowdsourcing, in not-for-profit contexts in order to address a lack of research into its use for non-pecuniary motives. It is known that crowdsourcing in these contexts tends to involve a mix of for-profit and non-profit actors. However, due to the prevailing focus on the interests of the firm, there is a need to develop more multi-level perspectives on open innovation involving individuals, groups/projects, business, ecosystems/communities, regions and national systems (West et al., 2014).

Crowdsourcing has been applied in open innovation within the public sector with examples including the USA Federal government's Challenge.gov platform, participatory budget making in Chicago and Calgary, and Finland's Citizens' Initiative Act (Aitamurto, 2012; Lee et al., 2012; Mergel and Desouza, 2013). A characteristic of this method is the dynamic interaction between members of the "crowd", who may be strangers or acquaintances connected only via the "weak ties" perhaps formed during the event. Weak tie connections between individuals with different world views can stimulate ideas and create innovative solutions by drawing on the multiple perspectives of the individual participants, more so than "strong tie" connections which may lack the richness of discussion due to similarity of experiences and viewpoints (Granovetter, 
1973). Furthermore, the virtual nature of an online crowdsourcing event enables the participation of a large number of individuals from across the world at comparatively low cost.

Crowdsourcing is a method applicable to our research question of how policy can encourage individuals to engage in and support sustainable entrepreneurship. It is consistent with our premise that individual actors have the potential to play a role in innovating towards system level changes. A multi-stage approach was used to design, implement and analyze a text-based online crowdsourcing event involving a diversity of stakeholders with the purpose of identifying existing or potential policies for sustainable entrepreneurship. Details of the methodology are summarized in Table 1 and detailed below.

\section{INSERT TABLE 1 ABOUT HERE}

3.1. Design: Given the significance of the one-off crowdsourcing event for generating data, a significant effort was devoted to the design stage including identifying broad areas of policy relevant for sustainable entrepreneurship, selecting the technological platform, preparing the moderators, identifying and briefing guest contributors, and recruiting participants representing a diversity of actor roles.

3.1.1 Identification of policy areas: We conducted a review of relevant literatures including policy and sustainable entrepreneurship to identify a short list of policy themes. We then checked these policy themes with actors representing a variety of roles, including entrepreneurs, consultants and academics, via face-to-face workshops. We also conducted oneon-one interviews with policymakers. (See pre-study sample profile in Table 2). This pre-work identified issues encountered at the policy decision-making level and the barriers and enablers encountered by sustainable entrepreneurs. Based on the combined methods listed, six policy themes instrumental to the success of a sustainable entrepreneur were identified: development of skills to encourage entrepreneurship and innovation (education); accessibility of funding for sustainable entrepreneurs (funding); networks to support a (frequently) solitary entrepreneur both with practical guidance and motivational support (networks); scaling up the venture once it has launched (scaling up); measurement of sustainable enterprises; and, the need for integrated policy mechanisms that support rather than hinder sustainable entrepreneurs (open policymaking).

3.1.2 Selection of the online platform and design of the online event: A number of options for the online platform were researched. The chosen technological platform was provided and 
hosted by a global research company with experience in running multi-participant text-based online forums. The company's expertise proved invaluable throughout the design stage, in terms of advice about optimal numbers of participants, numbers of "rooms" viable for multiple simultaneous discussions, briefings for moderators and guest contributors, and practical operation of the platform. Regular project planning meetings were held during the four months leading up to the event. Logistics were arranged for a physical event hub from which the discussion moderators and technological support team operated on the day of the crowdsourcing event. The event was called the Sustainability Innovation Exchange and a schedule of discussions on the event day was designed in collaboration with the research company and included one-hour discussions for each of the six policy areas outlined in 3.1.1 above education, funding, networks, impact, scaling up, and, open policymaking - plus opening and closing plenaries.

3.1.3 Preparation of moderators: Academic moderators with subject matter expertise and experience in conducting qualitative research were identified and recruited. In a similar manner to focus groups, a discussion guide was developed for each of the one-hour sessions (Denise Threlfall, 1999; Greenbaum, 1998). Each discussion guide comprised an introduction, three key questions for participants, illustrative examples and three specific policy suggestions to be put to participants in the form of polls. The guide helped to ensure that key issues would be discussed while allowing the moderator the freedom to manage the discussion as it flowed on the day. As the event was text-based, a key component of the discussion guide included some pre-prepared statements which the moderator could choose to paste into the online discussion if and when they deemed them appropriate. In the week prior to the event, each moderator conducted a dummy run in leading a discussion in order to familiarize themselves with the technology platform.

3.1.4 Identifying and briefing guest contributors: Between two to five guest contributors were identified for each of the discussion themes. They represented a diversity of perspectives including entrepreneurs, managers in large corporations, thought leaders and activists in NGOs, consultants, policymakers, and academics. The guest contributors were briefed in advance so that they were comfortable with the technical aspects of the method and with the moderator's broad plan for bringing them into the discussion. The guest contributors were encouraged to prepare some topics of commentary and to have at the ready any visuals or web-links that they might wish to post during the discussion. 
3.1.5 Recruiting participants: Participants for the crowdsourcing event were recruited from UK, Europe and worldwide via email marketing to databases, personal networks, and via social media, newsletters, posters and invitation postcards distributed by hand at relevant events. The target audience was deliberately broad: individuals from all backgrounds with an interest in sustainability, entrepreneurship, or both. The research team, the platform provider, moderators and guest contributors were all active in promoting the event and attracting participants. All participants were required to register before the event via the platform website. Registration captured email addresses to enable profiling of participants as well as member checks in order to ensure validity of data gathered. Over 340 individuals from 47 countries pre-registered to take part. An eventual 150 participants from 25 countries logged in on the day to participate in the crowdsourcing event. Participants were asked to self-select from amongst nine roles with the option of selecting multiple roles; $60 \%$ selected 1-2 roles while $36 \%$ self-selected more than three roles (as shown in the middle section of Table 2).

\section{INSERT TABLE 2 ABOUT HERE}

3.2. Implementation: The main data collection activity was a crowdsourcing event, termed the Sustainability Innovation Exchange, billed as a one-day online conference hosted jointly by a university and a professional research firm. The event aimed to crowdsource ideas for sustainable entrepreneurship from a number of interested individuals. Although the conference was virtual thus enabling participants with internet access to join from anywhere in the world, a physical hub was located in the UK to bring together the conference organizers, technical support, moderators and some guest contributors.

The conference schedule started with a 30-minute plenary session followed by three concurrent one-hour sessions on the themes of education, networks and funding. The afternoon continued with three more concurrent sessions on the themes of scaling up, impact and open policymaking. The conference closed with a 30-minute plenary wrap-up. Each participant was free to participate in as many sessions as they chose.

Moderators used the pre-prepared discussion guides to facilitate the discussions on each of the six policy themes. They encouraged participants to provide ideas for policies and examples of how these ideas might work in practice. Moderators furthermore seeded the conversation with specific policy proposals which had been developed in the pre-study and 
encouraged participants to vote on these. They invited participants to propose variations on these policy initiatives or even radically different initiatives. Group interaction was encouraged by the moderator in the same way as when moderating a focus group discussion. The ability to comment on other participants' ideas was furthermore facilitated by the technology which allowed participants to go back and add further comments on discussion threads throughout the day. Due to the text-based nature of the online crowdsourcing method, the resulting discussion was captured, and downloaded with the intention of subjecting it to textual analysis (Kozinets, 2002).

3.3. Analysis: A total of 1,696 unique comments were posted during the event. These were downloaded from the hosting website and uploaded to NVivo for analysis. These data then formed the basis for the subsequent analysis. The data was subjected to two rounds of coding by the research team: coding for barriers and enablers to sustainable entrepreneurship and coding of policy ideas. The policy ideas were categorized into a smaller set of higher-order policies with common purpose. The coding framework was validated by second coder checks. The subsequent framework was validated with members of the crowd at a face-to-face stakeholder conference. Details are as follows:

\subsubsection{Coding of barriers and enablers to sustainable entrepreneurship: Two separate} rounds of first-order coding were conducted by three of the authors. The research team started by coding the perceived barriers to, and enablers of, sustainable entrepreneurship by applying the Motivation-Opportunity-Ability-Behaviour (MOAB) model (Ölander and Thøgersen, 1995). The MOAB model applies to sustainability-oriented behaviour, where motivation represents the individual's internal and underlying reason(s) for a given action that drive(s) the individual's recognition of wants and needs, ability represents the individual's personal competences and resources to carry out a given action, and opportunity represents the external conditions supporting or impeding individual action. These three determinants are interdependent - for example, an increase in individual ability, such as by learning a new skill - often has positive spill-over effect on motivation and vice versa (Thøgersen, 2005). This model was chosen because it has been used successfully within the related field of sustainable end-user innovation (Nielsen et al., 2016) and in other studies of sustainable behaviour from a policy perspective (see Jackson \& Michaelis, 2003) and because it helps to account for the observed attitude-intention 
behaviour gap in much sustainability research, which is often not well explained by other behavioural models (see Devinney et al. 2010).

3.3.2 Coding of policy measures for sustainable entrepreneurship: Having coded the barriers and enablers in the textual data, the research team then conducted a second round of coding to identify policy measures. This second round identified actions for influencing the external context for sustainable entrepreneurship. The policy measures identified were explicitly linked to the barriers to be overcome and the related aspects of motivation, ability and opportunity. By applying a broad definition of policy to include all actions taken by national government or members of society, the coding process identified 49 policy ideas. For each policy measure, codes were generated for aspects that were supportive and aspects that challenged to the policy, as well as examples of the policy idea in practice.

3.3.3 Second coding of policy measures: An independent researcher familiar with the topic of sustainable entrepreneurship conducted second coding of the data. He was briefed to independently identify policy ideas as a validation exercise resulting in 55 policy ideas.

3.3.4 Categorization of policies: This coding structure was reviewed, discussed and iterated between the authors and the independent researcher. The research team discussed the emergent policy measures and after removing duplication and aggregating some measures, agreed on the final 46 policy measures. The policy measures were categorized into 17 higher order policy focus areas with common purpose. These were then clustered to produce five policy themes which broadly reflected the original six themes used to organize the crowdsourcing event but saw 'scaling up' predominantly subsumed within the 'building networks' and' access to funding' themes. Where there were differing views between the researchers, consensus was reached via discussion and via further iteration to arrive at the labelling and content of the final policy framework summarized at Table 3 . The aim was to ensure a coherent categorisation of policy while retaining full granularity of insights. The identified barriers and enablers were then mapped against the policy recommendations they motivated in order to present a full picture of the issues relating to sustainable entrepreneurship alongside the suggestions of how to address these issues.

3.3.5 Validation of findings with members of the crowd: Ten emergent policy recommendations derived using the final framework were shared with EU policymakers and other actors at three follow-up validation events, including presenting these findings at a societal 
conference involving multiple stakeholders. The roles of these 89 individuals in the post-study event are detailed in Table 2.

\section{FINDINGS}

Through inductive analysis of the 1,696 text comments posted during the crowdsourcing event, we develop a framework which sets out the five policy domains within which sustainable entrepreneurship can be encouraged: 1) creating skills and awareness, 2) building networks, 3) funding and investing, 4) measuring impact and performance, and 5) innovating governance (Figure 1). For each domain, we report on the individual-level motivational, ability and opportunity (Ölander and Thøgersen, 1995) enablers which these domains enhance, describe what the focus of the policies in each domain should be, and illustrate each of these focus areas with examples of policy measures recommended by our participants (Table 3).

\section{INSERT TABLE 3 ABOUT HERE}

\section{INSERT FIGURE 1 ABOUT HERE}

We find that the recommendations not only cross multiple formal government policy domains such as education and finance, as well as environment and innovation, but that these policies are enacted by a broad range of actor groups. A participant comment was coded to a "policy example' if it related to the need for a particular action to be taken in order to change the external context for sustainable entrepreneurship. So, while our findings include policies which could be implemented or supported by government (whether at city, regional, national or EU level), many of the suggestions would require co-implementation with government, or could even be enacted independently, by other non-governmental institutions (e.g. NGOs, businesses) or actors (communities or individuals). We explore this further in the Discussion section.

\subsection{Creating skills and awareness}

Education in its broadest sense - encompassing education for all ages and informal as well as formal education - was extensively discussed, gathering the most comments of all the discussion "rooms" during the crowdsourcing online conference. Awareness of sustainability amongst young people was seen as high - "good news is that kids now have green blood. And start-ups from graduates are often green by default" (Participant TL321 ${ }^{1}$ ) - however it was felt that new

\footnotetext{
${ }^{1}$ Participants have been allocated a letter to identify their role as per the sample table: $\mathrm{A}=$ academic, $\mathrm{B}=$ business person, $\mathrm{C}=$ citizen, $\mathrm{E}=$ entrepreneur, $\mathrm{I}=$ investor, $\mathrm{NGO}=\mathrm{NGO}$ member, $\mathrm{PM}=$ policymaker, $\mathrm{PSE}=$ public sector
} 
skills needed to be developed in young people, and wider society, to adopt sustainable lifestyles and seek solutions to the challenges posed by the process of this adoption.

Using the MOAB model discussed earlier, we identify the core individual motivational, ability and opportunity determinants emerging from our data as they relate to creating skills and awareness. Motivational determinants ranged from a need to (1) develop shared values, (2) act as role models and mentors, (3) have emotional resilience with a capacity to accept failures and overcome feelings of isolation, (4) draw motivation from visible sustainability impact; and (5) have the entrepreneurial abilities to be persistent and committed in engagements.

Based on those motivations, participants noted that a discrete skill set was necessary in educational, organizational, project-related, and individual contexts. Participants gave examples of ability enablers that would support change in these contexts, such as collective problem solving skills or the ability to involve and educate parents in education. Other important competencies identified were skills in the management of projects and organizations, individual creativity and personal development as these skills support the development of an entrepreneurial skills set. Enabling abilities were therefore found to be spread across different contexts and engaged individuals to foster awareness building and skills development.

Participants also discussed a range of opportunity enablers relevant to support reforms. For example, educational curricula on sustainability, innovation and entrepreneurship were seen as a necessity, but also a culture that is more accepting of failure would support learning. In addition, different approaches were proposed that included gamification, volunteering, and flexibility in the creation of class curricula. Participants also proposed that engagement opportunities for learning could be fostered between companies and local communities so that each actor could learn from each other. In summary, interdisciplinary learning and engagements as well as a resilience culture (learning from failure) were seen as enabling opportunities to foster learning for sustainable entrepreneurship.

Following from these determinants, participants identified two areas of policy focus that would foster the creation of awareness and skills: encouraging experience-based learning and changing learning-based education.

employee, $\mathrm{TL}=$ thought leader. Where multiple roles were selected by the participant, the authors have allocated the role that best represents their comment. The numbers are a unique identifier for each participant. 
The first cluster of recommendations was to encourage experience-based learning. Here, role models and mentors provide motivational support and also showcase the need for emotional resilience, as well as the development of empathy, compassion and purpose. In addition, the skills needed for sustainable entrepreneurship are enabled particularly in instances where problem-solving, project management or organizational skills are put into practice.

A sense of society and community and experience of work should be encouraged from an early age via volunteering and/or the Sustainable Entrepreneurship scheme ${ }^{2}$ and facilitated by lifelong and informal education including experiential learning thereafter. Mentoring and coaching were discussed as tools to aid entrepreneurs develop the entrepreneurial and business skills required later in life. Universal Basic Income (see also 4.2.5 last para) could support this where income is a barrier to self-managed learning in multiple contexts. This lifelong, selfmanaged pursuit of learning could be a societal driver for reform of the formal education system. Moreover, this type of learning fits within a more holistic view of education as a means of developing society to create and access the opportunity level to meet the needs of the future generations, and supporting the adoption of sustainable lifestyles: "In the education session this morning I was struck by how many of the changes needed within the education system would best be tackled through interventions outside the education system" (TL192).

The second cluster related to the need to change learning-based education, to include sustainability and innovation in both formal education for all students (children or adults), and informal sustainability education delivered via work-based training programmes, digital platforms or other means to allow those in full-time work, parents and educators themselves to address the current lack of prioritisation, understanding and abilities regarding sustainability. Through learning-based-education, individuals could benefit from embedded knowledge on sustainability and innovation curricula that motivate individuals through a higher visibility of sustainability impacts, and also increase the life-long exposure to sustainability-related education. A policy focus on learning-based education also drives entrepreneurs' ability to invest in personal development and train reflexivity and creativity.

The intention would be to create and maintain a motivation to innovate for sustainability within all sectors and age groups in society. In schools, any current focus on sustainability was seen as being ad hoc, revolving around events such as Earth Day. An issue discussed was the

\footnotetext{
${ }^{2}$ www.se-award.org/en
} 
lack of sustainability being part of consistent, cross-curricular learning. Within higher education, many business and management degrees restrict CSR, ethics or sustainable business to a single module, creating a strong sense of differentiation from "normal," purely for-profit business. The discussion focused largely on the UK school and university system but there were participants who also contributed their views and student experiences from China, Germany, Australia, Italy, Belgium, Spain, USA, South Africa and the Netherlands, amongst others.

A number of examples were given of innovative programmes fostering the abilities of individuals to innovate for sustainability, based on Tiimiakatemia methodology $y^{3}$ and the International Institute for Creative Entrepreneurial Development's ${ }^{4}$ principles for entrepreneurship, to develop leaders who collaborate successfully rather than act as a "lone hero," a role often seen as full of difficulties when adopted by a sustainable entrepreneur who may need partners, supporters and advisers to access finance and markets. There was discussion about how best policy could drive the use of sustainability and environmental education resources $^{5}$, into school education without overburdening schoolteachers, and also discussion of the Principles for Responsible Management Education (PRME) ${ }^{6}$ being more widely applied in higher education. Some successful examples were noted such as the Barcelona School Agenda 21 programme which has inspired schools beyond the city to adopt their programme, and La Rochelle business school which has mandated a service element within its degree.

However, the issues in replicating such programmes and embedding sustainability and innovation in curricula for all ages and contexts were seen as insurmountable in the current educational policy climate of increasing specialisation where students progress through their learning from primary to secondary school, and from secondary school to university. As stated, national curricula are seen as being largely inflexible and focused on individual attainment targets rather than allowing teachers to deviate from rigid and siloed curricula to include nonprioritised topics such as sustainability, innovation or entrepreneurship, nor fostering the "soft" and more innovative, entrepreneurial and character skills required ${ }^{7}$. A consequence of the lack of

\footnotetext{
${ }^{3}$ Tiimiakatemia is a Finnish Centre for Entrepreneurship which now has an international leadership following using its methodology (www.tiimiakatemia.com)

${ }^{4}$ www.uwtsd..ac.uk/iiced

${ }^{5}$ SEEd is a UK non-profit organisation awarded UNESCO Key Partner status in the UNESCO Global Action Programme on Education for Sustainability Development (www.SE-EEd.org)

${ }^{6}$ www.unprme.org

${ }^{7}$ See for example World Economic Forum's Skills for the 21st Century, "New Vision for Education: Fostering Social and Emotional Learning through Technology", Mar 2016 (www.weforum.org/reports/new-vision-for-
} 
these skills was stated as being adults who have a limited ability to assess and take measured risks and who are therefore less likely to innovate for sustainability. Participants argued that there is a need for a reform of the education system because future challenges "... will require from educators to believe in sustainability as future imperative, from educational institutions to be embedded in sustainable practices, and from educational policymakers to bring curriculum development and educational infrastructure in line with such an orientation" (TL192). Community or free schools were posited as a possible way to encourage self-managed, independent learners who take responsibility for developing their own skills sets. Proposed higher education policies such as privileging universities which achieve higher levels of graduate employment may also encourage a risk-averse corporate approach to business teaching, and coupled with financial restrictions such as student loans may actively discourage innovation. There was also concern about the commercialisation of higher education itself stifling innovation and therefore a desire expressed to separate universities from profit-making goals.

\subsection{Building networks}

The need for collaboration was an underlying theme throughout the crowdsourcing event, with the participants reporting networks - both formal and informal - as key to providing them with important practical and emotional resources. Using the MOAB model discussed earlier, we identify the core individual motivational, ability and opportunity determinants emerging from our data as they relate to building networks.

Considering motivational determinants, many participants noted that the entrepreneurial journey can be a lonely one, mired by periods of great stress and confusion about the direction in which they are going: "Entrepreneurship is a lonely process at times which is characterized by many ups and downs; a bit like a roller coaster. Entrepreneurs need to bounce back from adversity and hence need to be resilient" (A259). Sustainable entrepreneurs therefore need a certain level of emotional resilience towards the ups-and-downs of process, especially experiencing failure. Here, role models were an important source of inspiration, while mentors offered key motivational support throughout the entrepreneurial process. These mentors were typically found through entrepreneurship clusters both digital and physical - while conversations

education-fostering-social-and-emotional-learning-through-technology) and Business for Social Responsibility's Sustainability and Leadership Competencies for Business Leaders, October 2012

(www.bsr.org/reports/BSR_Sustainability_Leadership_Competencies.pdf ) 
with successful entrepreneurs often served to re-solidify the individuals' belief in what they were doing. These networks allowed individuals to develop their own success (or survival) stories critical for future success. Conversely, others noted that experiences with unsuccessful or irrelevant networks or conferences served as key sources of irritation. Importantly, the success of networks is influenced by the created culture within the network, and trust between the members.

In terms of the ability determinants, networks serve both as a key resource for entrepreneurs, but conversely also require skills and abilities to make the most of the opportunities they offer. Participants said that their networks granted them access to a diversity of people with different skills - providing them practical project and organizational management skills. However, individuals also need time, money and mobility to participate, particularly in physical events. Individuals must also be willing to engage and talk about both their positive and negative past learning experiences. Sharing past failures is at times seen as a reputational hazard, because of a culture where failure is, in theory, accepted, but rarely celebrated in reality.

Finally, the key opportunity determinants were the existence of either institutionalised formal formats (e.g. entrepreneurship clusters, conferences) events or informal networks (e.g. online forum and social media). "For me, green economy conferences and events help drive innovation and positive thinking/collaboration" (B321). They wanted one-stop-shops where sustainable entrepreneurs could access a diversity of tools and resources, but commented that these were often hard to find, because government platforms typically relate to specific domains, resulting in a fragmented array of different relevant platforms and networks.

Policy can therefore enable sustainable entrepreneurship through the creation and maintenance of knowledge networks, helping entrepreneurs to identify new ideas, and leveraging existing knowledge through collaborations.

Creating and maintaining knowledge networks. There was support for the idea of governments hosting a national (and/or even international level) database of ideas' bringing together information relating to sustainable innovations e.g. the technology used, likely financial return and likely positive environmental impacts. This database would improve access to role models, and also offer a source of inspiration and insights on how individual ideas can be implemented and have a positive social / environmental impact. However, participants said it was the human stories of success (see also 4.2.4. final para) which were the most important, leading to suggestions for more of a portal for sharing and publicising stories. It was also 
important to improve network interfaces - networks should not forget to reach out to other networks, including but not exclusively, powerful and established networks such as industry associations, the National Academies blueprinting the innovation policy of governments, and policy think tanks. This quote illustrates this point "In some ways, the (German) Council for Sustainable Development tries to work on this interface by providing competitions and small roundtables linking up sustainable entrepreneurs and policy consultants" (A24) but goes on to reiterate that it is individual people who define the success or otherwise of these networks and collaborations "it is a lot about PEOPLE who are members of several networks and who can easily act as interfaces."

Identifying new ideas. Crowdsourcing and open innovation events were seen as a method to access ideas from a broader base of individuals, with participants citing examples including WHO (crowdsourcing solutions for the Ebola crisis), MIT / NASA and Citizen Labs ${ }^{8}$. These visible examples of success in identifying new ideas serve as sources of inspiration for sustainable entrepreneurs both through the specific ideas generated, but also the individual role models involved. Involvement in these crowdsourcing and open innovation events also enables individuals' ability in terms of project management and organizational skills, but also personal development. Finding better ways to develop and share IP was also a key discussion area, with participants suggesting "HEI funding that rewards universities, etc which actively mobilise resources (faculty, IP, seed capital) to support innovation clusters / small business development (e.g. Manchester in the UK, Leuven in Belgium)" (TL192), government incentives for corporates to fund university research, and for businesses to open source their patents (e.g. Tesla), "essentially allowing innovators to crowd source the next generation of green technology" (E225). Whilst some entrepreneurs felt it was important that IP laws still acted to protect the value of their ideas, many shared this sentiment: "I want to share ideas, I'm not worried about losing them, I trade on my skills in making ideas happen" (E225). Participants gave examples of both formal and informal networks and hubs where these new ideas can be found with some suggesting that perhaps formal networks help entrepreneurs navigate the landscape and scale up their concepts (learn how to be an entrepreneur), while informal networks may be the place when the genuine sparks of new ideas, are ignited, or where good ideas are 'cross-pollinated' between people in a new and exciting way.

\footnotetext{
${ }^{8} \mathrm{http} / / /$ citizenlab.co
} 
Leveraging knowledge though collaboration. This focus area relates more to the type of networks which can help get the most of the knowledge and ideas which are 'out there' by developing and or recombining them. Different types of formal networks were reported as having a role to play. These included government-funded networks such as the Knowledge Transfer Network (KTN) and the Catapult Centres in the UK, university run networks, such as the Business Growth Club at Cranfield School of Management, UK, and not for profit networks - particularly Impact $\mathrm{Hub}^{9}$ which runs 86 hubs in cities across the globe. These hubs run mentor programs and help members understand and articulate the potential impact they could have helping them to persist in their endeavours. Informal networks were also discussed. These are more self-organising, ad hoc and virtual networks which sometimes form around organized events. The benefit of these networks is their flexibility and lack of predefined agenda, which can leave space for the unexpected: "unexpected collaborations can be the most productive" "Design the initial network with clear values and purpose but ensure it is only lightly structured, so that it can change flexibly and internally as it goes forward. Don't try to predict too much, leave plenty of gaps for exaptation (serendipity). Be prepared for it to get chaotic" (E225, B321). These informal networks drive engagement through like-minded interests, and therefore reduce people's fears of sharing with others, because of the trust between members.

\subsection{Funding and investing}

Perhaps unsurprisingly, access to finance for sustainability entrepreneurs was a significant theme. The central motivational determinants as they relate to funding and investing focused primarily on the characteristics and expectations of potential funders. For example, a willingness to forgo immediate gains and exercise a greater willingness to take risks with new experimental ideas was seen as key enabler. Participants in general noted that more multifaceted investment profiles were especially important for sustainable entrepreneurs. "Many of the financial opportunities in this area require a different view of the exchange between, or relationship with, clients, customers or consumers" (A27).

In terms of the ability determinants, some themes that came up apply for sustainable entrepreneurs and entrepreneurs alike, for example, project management skills and organizational skills were noted as core competences for successfully achieving funding. However, a key

\footnotetext{
${ }^{9}$ www.impacthub.net
} 
difference is that sustainable entrepreneurs also need to able to illustrate their impact, and therefore be able to measure it across environmental and/or social as well as economic domains.

The opportunity enablers relating to funding and investing included formalised opportunities, such as platforms linking people to specifically relevant funding opportunities, and an identifiable status for sustainable ventures which could attract impact investors and/or be tied to tax breaks for investors. Participants also commented on a need for more consistent, joined-up government policy for sustainable entrepreneurship, instead of having fragmented policies that on the one hand incentivise sustainable ventures, whilst at the same time supporting unsustainable industries.

In summary, at the opportunity level, key opportunity enablers relate to reforming the financial system to prioritise longer term returns and social and environmental values. From an ability perspective, enablers relate to the individuals' ability to identify and secure the funds that might be available: " $A$ whole spectrum of private and public impact investors are coming to the forefront....but it is still an opaque market and difficult to navigate for entrepreneurs" (I221). There is therefore a need to reorient the financial system and public investment towards supporting sustainable entrepreneurs, to create interventions which incentivise private investors to prioritise more sustainable projects, and to make the identification of sustainable investments easier. Our recommendations here therefore fall into three focus areas.

Governing sustainable investment comprises government policies which could help reorient the financial system itself "so it's more long term (time wise) and broad (thinking wise)" (I221). This included ideas about how the government could influence this transition through government-funded green investment vehicles such as the UK's Green Investment Bank (now privatised), subsidies and grants, or even stock market reform to "limit liquidity to support sustainability." (I142). These policies would support access opportunities for sustainable entrepreneurs seeking funding with longer return horizons, as well as demonstrating a greater willingness to forgo immediate economic returns in favour of long term social and environmental benefits.

Prioritising funding flows is concerned with encouraging private investment. Our participants suggest that crowdfunding could be particularly helpful for sustainable entrepreneurs because individual investors can 'vote with their wallets' "because they really believe in the project” (A27). The suggested role for government extended from direct funding of specific 
sustainability-oriented crowdfunding platforms (such as Ecocrowd in Germany), to the cofinancing of specific sustainability projects, to the development of an EU regulatory framework to better protect crowdfunders. This may enabler more non-financially motivated investments and potentially let sustainable entrepreneurs experiment with ideas as the sources of income grow. Incentivising investment from corporate venture arms (which in 2014, invested c. $\$ 5$ bn into venture companies, the highest level of annual corporate venture investment since the dot.com era also emerged as an opportunity, which government could support though cofinancing vehicles, or tax breaks. Here, sustainable entrepreneurship status would be central in identifying for business what is a sustainable venture as compared to other start-ups. These investments offer additional non-financial resources and access to markets; despite this, there were fears that these investments can make it harder for start-ups to challenge established regimes: "You can end up feeling you're propping up an old model, or helping an incumbent with a very defensive play” (B102).

Finally, there was broad agreement that establishing a legal form for sustainable ventures would help both public and private investors to recognise and compare sustainable ventures, and could facilitate prioritised funding flows to them. "I like the idea of Sustainability Entrepreneur status for startups. When we started [our firm] we wanted to take sustainability into consideration and made minor contributions such as using Green Tomatoes as our taxi firm and we tried to sort out recycling (which I was surprised to find was harder for business than for private individuals), but having a status to achieve would have provided guidance about what we could and should have been doing as well as providing recognition” (B279).

\subsection{Measuring impact and performance}

The next theme which emerged relates to the ways in which the performance of sustainable ventures is measured, and how their potential and actual social, environmental and economic impact should be evaluated. Entrepreneurs reported finding it difficult to measure and communicate the effect of their work, and managing against multiple measures of value increases the complexity they face in running their businesses. The traditional measures of financial return used to develop business plans and attract funding, are not sufficient to communicate the potential long-term value offered by their ventures, to compare across ventures, or to prioritise at a macro level which types of entrepreneurial innovations should be supported. 
The insights and recommendations from our participants in response to these barriers fall into five clusters. First is the need to set vision and direction within an organization, through a conscious choice of what to measure, in the context of the purpose of the organization: "What you measure becomes what matters: it shapes your organisation as much as leadership, vision, values" (B231). For a business this plays a role is creating and articulating the value proposition "choosing the indicators of impact and make communicating that PART of the product branding" (B231). For government bodies this involved giving a "clear steer about priority sectors and set the 'direction of travel',' (A27) which can transcend political cycles.

Scoping impact includes recommendations about what should be included in impact measures. There was agreement that measures should be much more multifaceted than carbon emissions, and take into account multiple stakeholder needs in order to give a holistic view of impacts, recognising the possible unintended consequences of one part of a system on another. At the same time, these measures need to be comparable across innovations and organizations. There was a call for measures that were more positive and regenerative - focused on doing good, rather than 'less bad.'

Building on this, recommendations on accounting for complexity discussed the need for interconnectedness between policy domains so that "innovations add up to system change" and to avoid unintended consequences. The 'wellbeing' framework (comprising both health and sustainability policies) which Wales has embedded in its constitution was used as an example of this: ${ }^{10}$ "What's clear is that you can't deliver systemic policy through silos" (A7). In this cluster, there were also insights about measuring 'what might become' - so not to restrict the scope of innovation with a rigid adherence to current measures: "We are in a quantum world where the things we are measuring are merely potential and as soon as we measure them we have lost the bigger picture" (TL312).

Developing better models brings in the conversation about the types of models that could be used to achieve the objectives outlined above. Participants referred to the usefulness of IOOI measures (input, output, outcome, impact) which specifically look beyond output to impact, and even the need to consider multiple layers of impact - "the direct and indirect impacts of an innovation on a sub-system (e.g. energy system - could also be a city) and on society, and on the

\footnotetext{
${ }^{10}$ Well-being of Future Generations (Wales) Act (http://thewaleswewant.co.uk/about/well-being-future-generationswales-act-2015)
} 
paradigm that guides society" (TL312). There were suggestions that we need both quantitative and qualitative approaches for measuring impact such as the Transformational Index tool which asks organisations to describe what sustainability means in their context and then develops their indicators of impact within that vision.

Finally, there were ideas about using impact measurement and communication to drive behaviour. It was argued that the successful communication of positive social and environmental impacts, through both the telling and sharing of stories, and the distribution and publication of awards, could help to change a society's narrative about what constitutes success and therefore evolve the measures that matter to people. This cluster of recommendations also includes discussion on the ways in which companies could improve reporting against impact measures and how this could then change the behaviour of investors. The theme of impact therefore links closely with the funding and investing theme.

\subsection{Innovating government}

This last domain comprises clusters of recommendations which concern the public policymaking process itself, and how it could change to become more conducive to supporting sustainable entrepreneurship. There are overlaps and links here with the four preceding domains, however, the recommendations here differ in that their implementation could only be led by government, not by alternative actors or organizations. Changes therefore not only revolve around specific policy domains that are relevant for sustainable entrepreneurs, but also around the process by which policy is made and implemented.

From a motivational perspective, the way current policy process is viewed by a significant number of participants at the crowdsourcing event was one characterised by a significant degree of cynicism/pessimism: "We need to address the democratic deficit. As in wider life, participation is limited by cynicism largely based on experience - 'why bother?'" (B225). This lack of engagement was claimed to be undermining many people's willingness to make decision and take action. Sustainable entrepreneurs therefore needed to be armoured with a high degree of emotional resilience to overcome this cynicism. Here once more success stories especially easy and quick wins - were seen as key enablers.

From an ability perspective, it was argued that there is an intrinsic tension between the traditional approach to policymaking and the need for such policy to encourage innovation: "The problems with policies are that they seek uniformity and standardisation. Sustainability 
innovation needs experimentation (although within the boundaries of responsibility) and diversity. We therefore need policies that encourage emergence and innovation, something that public authorities seem not to be comfortable with" (TL312). More adaptive policies depending on the actor in focus would help create more room for experimentation.

Finally, policymakers could to a greater degree rely on open innovation challenges within government to experiment and pilot-test with different policy approaches: "Recently the concept of open innovation that originated in business has been introduced to solve social problems, which can be adopted by decision makers or planners. Also, experiments are prerequisite" (A7). In line with experimentation, a number of participants also said that there was a need for more behavioural oriented tools (e.g. nudging) that take into account individual behaviour and not just macro-economic models. These behavioural tools once more linked to measuring impact - "I think the idea of measuring whether the policy you have implemented actually has the desired effect is key" (A96). Finally, greater stakeholder involvement and transparency about existing stakeholder involvement was called for: "We tend to get better ideas and stronger inputs as a result of exploring broader perspectives on an issue other than our own. Being stakeholder centric is a mind-set which pays dividends" (B313).

Within this domain, the recommendations were therefore centred around accepting the greater role that the citizen can play within the policymaking process, implementing tools to enable more niche integration and innovation, and in the later stages of sustainable entrepreneurial journey - e.g. scaling-up - conferring trust to market forces and levelling the playing field. We grouped these recommendations into five policy focus areas.

Firstly, innovating the policymaking process emerged as a key focus due to an intrinsic tension between traditional policymaking and the policymaking need to encourage innovation. Participants suggested that ways should be found to encourage innovation and risk taking in policymaking, including more experimentation and agile testing / trialling of policies and learning from those to improve (test-learn-adapt). There was agreement that the inclusion of a wide range of stakeholders in a more open approach to policymaking would help develop more innovative policies. Participants provided examples of where this is being done in countries as diverse as Mexico, Denmark and the $\mathrm{UK}^{11}$. These fora were seen as good first steps to creating a culture of engagement where citizens are involved in the policymaking process. There was some

${ }^{11}$ For example: www.participatorycity.org/\#discovered 
discussion on the new types of policies which are emerging - such as behavioural nudging and voluntary agreements. Finally, there were comments on the need to decouple policy from shortterm political cycles.

A second cluster of comments centred on removing policy barriers in the form of bureaucracy, red tape and onerous or contradictory regulation. There was a sense that the role of governments was to set the right boundary conditions, so that market forces could support the scaling up of more sustainable propositions: "The government has to provide the right conditions, like regulations, limited bureaucracy, can help with smaller things like providing incubator office space, but mostly: should not block matter, be mostly absent and let the market do the scaling up" (B225).

The following quotes puts these two themes together: "What we need policymaking to be is collaborative and is a learning institution" (TL192); "where policy is seen almost as hypothesis and implementation as test with a feedback loop to policy that helps it adapt. That means overcoming the hard distinctions of market and government and seeing them in a systemic way" (A7).

On the other hand, there was support for governments maintaining existing policy approaches with respect to sustainability more generally, namely pricing-in externalities, making sustainable purchasing choices themselves, and incentivising the eco-efficient behaviour of businesses and individuals. Some comments specifically pointed out the need for policy to complement these approaches with an increased focus on supporting sustainable entrepreneurship - tying this theme back into the other four described above.

There was also a thread of discussion around governments providing a 'universal basic income' which it was argued could help free up potential entrepreneurs from the restrictions of traditional employment (and debts) to contribute their time to community projects or their own entrepreneurial ventures - "I also see it as People's Venture Capital for sustainable entrepreneurs" (PM231).

\subsection{Sustainable entrepreneurship policy as a multiple level phenomenon}

The policy domains described above include policies which would be implemented or supported by governmental institutions (whether at city, regional, national or EU level). However, at the other end of the scale, there are policies which would be enacted by individuals or communities. In between, there are examples which would be enacted by other organizations, such as 
EUINNOVATE

businesses, venture capitalists, or NGOs. Policy for sustainable entrepreneurship needs to be conceptualised as a multi-level phenomenon, rather than a top down process originating only from national governments. Figure 2 illustrates this and provides examples of policies which would be enacted predominantly at each level.

\section{INSERT FIGURE 2 ABOUT HERE}

For example, within the domain of building networks formal government-funded networks could be enacted directly by government at national or local level. There was also support for these networks being hosted by universities (indirectly funded by government). However, participants argued that there was also a role for formal networks which were independent of government, run by, for example not for profit organisations such as Impact Hub, ${ }^{12}$ as well as for more informal networks organized by individuals. Policy should not only encompass direct actions that can be directly taken by government but also how government can set the stage in indirect ways for supporting action to be taken by other actors at the regime level (e.g. universities, NGOs) and at the niche level (e.g. individuals and communities).

\section{DISCUSSION}

Our findings contribute to the sustainable entrepreneurship (Table 3) and entrepreneurship policy (Table 4) literatures with an emergent framework for designing and implementing policy interventions to support sustainable entrepreneurship (Figure 1). We also contribute to the literature which uses the multi-level perspective (MLP) to explore socio-technical transitions (Geels, 2002; Geels and Schot, 2007) by conceiving policy not just as a stabilising force within an existing socio-technical regime, but also as a catalyst for change which can accelerate and aggregate niche-level innovations (see Figure 3). Our findings also offer a new perspective on the types of entrepreneurship policy levers which are more salient for sustainable entrepreneurs, and suggest how sustainability policy could be extended to include policies which foster sustainable entrepreneurship. These further contributions are discussed in the following sections.

\section{INSERT FIGURE 3 ABOUT HERE}

\footnotetext{
${ }^{12}$ For more information on Impact Hub: www.impacthub.net
} 


\subsection{The role of sustainable entrepreneurship policy in the multi-level perspective}

Since sustainable entrepreneurship is generally conceived as an individual-led phenomenon, and policy development and implementation as a top-down, institution-led one, we use the multilevel perspective (MLP) as a theoretical tool to integrate these perspectives. Within the MLP, policy forms a part of the established socio-technical regime and is usually assumed to act as a barrier rather than an enabler of niche innovation, because it serves to maintain the current sociotechnical arrangement and therefore established practices. However, in the context of sustainable entrepreneurship at least, our findings suggest that policy also has the potential to act as a catalyst for change by facilitating and aggregating innovations coming from the niche level, which in turn challenge and evolve the socio-technical regime itself. Our research also shows that the measures required to improve the context for sustainable entrepreneurship are enacted not only in institutions located in the socio-technical regime, but also by individuals at the niche level (see Figure 2 above). Figure 3 compares the original visualisation of the MLP with our proposed adaptation.

Figure 3 suggests that rather than viewing policy as purely enabling incremental rather than radical innovation, as proposed in the traditional MLP, we should instead conceive of a situation where policy can and does enable (and act as a barrier to) both. Certain policies create a context that is "dynamically stable", while other policies serve to promote radical niche innovation and hence socio-technical change. This form of "organized hypocrisy" emerges as various stakeholders all have positive demands that are not easy to satisfy as "success in one dimension often decreases success in another" (Brunsson, 2003, p.204). The paper therefore argues that policy actors can exercise both what we have labelled as stabilising policies that benefit the status-quo and niche enabling policies that support niche innovations; and furthermore, often do so at the same time. Nevertheless policy remains at the moment primarily focused on incumbents given their scale and resources, while niche innovators continue to be underexplored not least from a policy perspective (Bogers, 2011; Nielsen et al., 2016).

In contrast with this current focus of policy practice, our findings suggest that policy can play a proactive role in supporting niche innovation by specifically supporting sustainable entrepreneurship through the five policy domains we have identified (Figure 1). These policy interventions act at multiple levels, from directly changing the way in which policy is made at the socio-technical regime level (see section 4.5 above, Innovating government) to enabling 
small niche innovations through, for example, mentoring support and coaching sessions for sustainable entrepreneurs. These multiple arenas for policy interventions, as illustrated in Figure 2, thus enrich the MLP by suggesting that policies for supporting niche innovation can also be enacted by incumbent industries, such as through corporate venturing. We therefore suggest that the division between a dynamically stable and incrementally oriented socio-technical regime on the one hand, and a radical innovative niche on the other, creates a dichotomy that is not necessarily reflective of how a sustainable transition process occurs. Rather, there may from an early point be a symbiotic relationship between incumbents supporting niche innovation agents in various capacities (see for example Hockerts and Wüstenhagen, 2010). Hence not only can policy actors play enabler and barrier roles simultaneously, but policy itself is also enacted across various levels resulting in for example, certain incumbents supporting socio-technical change while others actively seek to oppose it.

We also find that creating the conditions for sustainable entrepreneurship requires changes to other aspects of the established socio-technical regime - not just policy. The role of education was one of the most passionately discussed themes of the crowdsourcing event, because a change in education was seen to be so instrumental in creating a culture which was more supportive of sustainable entrepreneurship: "There was a huge amount of energy around the education session - which tells me that there are systemic issues around what we are brought up to pursue as 'success' in our society that need to be changed" (A27). Similarly the role of industry was an implicit theme, particularly in the discussions around corporate venturing, with the financial industry specifically seen as playing an important role in facilitating sustainable entrepreneurship in the future.

There were also comments which referred to the need to 'change the system' or the dominant paradigm, represented by the landscape level (or exogenous context) of the MLP, if we are to achieve the scale of change required to transition toward a more sustainable future: "We need our financial system to incorporate environmental and social externalities. We need new forms of exchange that unhook us from a growth model. And we need a consistent and long-term framework for managing societal development that sees human, social and environmental systems as entwined and interdependent” (TL312). 


\subsection{Incorporating sustainability into entrepreneurship policy}

Audretsch et al. (2007) set out a framework which identifies six channels of intervention that can shift the demand for or the supply of entrepreneurs in a country or society (a summary of these channels is at Appendix 2 for convenience). This paper proposes a framework for considering policy in the specific context of sustainable entrepreneurship. Comparing these two frameworks, we identify three ways in which our framework contributes to this work on entrepreneurship policy in general, and some emerging patterns that can be developed in future research to deepen our understanding of policy for sustainable entrepreneurship. Firstly, the large majority of our recommendations can be classified as belonging to the 'supply side' of Audretsch et al.'s (2007) framework. They are related to the 'bottom up' issues of how to equip individual entrepreneurs with the capabilities and resources to be successful, and how to influence their preferences towards being an entrepreneur and the individual decision- making process used to evaluate the entrepreneurial option versus employment or unemployment. This is the part of the pre-existing framework which seems the most salient in the context of sustainable entrepreneurship and where our findings add the most granularity and new insight. Secondly, our policy domain of measuring impact and performance is a significant new addition to the previous framework. Audretsch et al. (2007) implicitly assume that the objectives and success measures for entrepreneurship are universally accepted and do not include them as a variable that policy could or should influence, whereas we find that this is a critical factor for sustainable entrepreneurship. Thirdly, we observe that the existing framework focuses on the launch phase of the entrepreneurial journey, on getting entrepreneurs into the marketplace, whereas our findings reveal the importance of the growth and replication of entrepreneurial ventures in order to achieve transitions to a more sustainable society. We therefore add a longitudinal dimension to the policy framework.

By bringing the MLP perspective to our framework, we also offer a broader conception of the channels through which policy operates, directly and indirectly, on the phenomenon of entrepreneurship. Although Audretsch et al. (2007) recognise that entrepreneurship policy embraces "a broad spectrum of institutions, agencies and different constituency groups" (Audretsch, Grilo and Thurick, 2007, p. 2) their policy examples are all top-down government policies, whereas our findings show how policy across five domains can be enacted at different levels of society (Figure 2). 
Our research further suggests that three types of innovation are needed in the policymaking process itself. Firstly, we highlight the need for policymaking to become more open, so that these individual-level and organizational-level constituents can be better engaged in supporting sustainable entrepreneurship. This finding supports Foxon and Pearson's (2008, p.153) recommendations that sustainable innovation policy should be enhanced by "promoting public/private institutional structures to enhance regulator/regulated relationships and stakeholder activities" and "ensuring broad stakeholder participation, particularly from the 'innovation constituency." Secondly, we suggest that policy should be more experimental and iterative, and involve continuous learning. This aligns with previous research which has found that "the structure and prevailing culture of government is almost antithetical to the habitually risky nature of disruptive innovations" (Chalmers, 2012 p. 20), and therefore change is needed towards "an iterative policy style mature enough to recognise the value in acknowledging and learning from failure as well as success" (Seyfang and Smith, 2007 p. 590) resulting in "policy learning' (Foxon and Pearson, 2008). Thirdly, our evidence suggests that innovative policy instruments are likely to be an important part of the policy mix required to drive sustainable innovation, supporting Rennings' (2000) argument that incentives and regulations must evolve with technologies. These innovations in the policymaking process will also require changes in the policymakers themselves, in terms of their ability to work with stakeholders outside the political system, take risks and think more creatively about their channels of influence.

\subsection{Incorporating entrepreneurship into environmental policy}

The literature on environmental policy also recognises the broad range of types of policy interventions which are required to bring about positive environmental change (Foxon and Pearson, 2008; Gouldson et al., 2008; Persson, 2006; Rennings, 2000; Taylor et al., 2012, 2013b). "Direct regulation has been supplemented with regulatory approaches that do not enforce mandatory changes to behaviour on regulated parties, but instead seek to harness other social forces, such as the buying behaviour of consumers or customer-supplier relationships amongst business, to influence business and individual behaviour" (Taylor et al., 2012, p. 271). Despite this, policymakers' conception of the role of individual actors is still commonly limited to that of relatively passive consumers (see for example Taylor et al., 2013a, Figure p. 492) whose primary roles are to 'choose products' and 'monitor performance' (of companies). By contrast, our finding indicate that the 'softer' instruments identified in Taylor et al.'s, (2013b) typology, 
particularly support mechanisms and capacity building, are likely to be critically important for driving sustainable entrepreneurship (see Table 4), through enhancing the skills and abilities of individuals. More research is needed into how these softer measures can be implemented at different levels of government (community, city, regional, national) in order to foster sustainable entrepreneurship.

\section{INSERT TABLE 4 ABOUT HERE}

\section{IMPLICATIONS FOR PRACTICE AND RESEARCH DIRECTIONS}

This paper proposes a framework which is intended to be used in practice to stimulate systematic thinking on how policy can encourage sustainable entrepreneurship. This focal contribution of a policy framework for sustainable entrepreneurship therefore has direct implications for policymakers. This framework has indeed begun to be applied in practice, by the authors in consultation with the Academy of Business in Society (ABIS), in the context of the EU. Table 5 shows ten specific EU-level policy recommendations which were derived from the framework and shared with EU policymakers and other interested stakeholders at three validation events, where we gathered insights on their relevance and practical implementation (see step 3.5 in the Method section). The framework could similarly be used as a policy development tool within a specific industry context or with governments at a national, regional or local level.

\section{INSERT TABLE 5 ABOUT HERE}

This paper also offers policymakers a practical example of how policy can be crowdsourced from a diverse group of stakeholders, and outlines a step-by-step method for running a similar policy innovation process in Table 1 . This method could itself be usefully refined in future. For example, while the crowdsourcing event generated high levels of engagement and input from a diverse set of stakeholders, our sample was not intended to be representative, which might be a requirement of a government-led crowdsourcing exercise. Policymakers were under-represented at the event due to the difficulty in recruiting them and securing commitment to taking part. Participant feedback on the experience of the event was generally positive; however, some felt that the pace of the discussion was too fast to keep up with in a text format, and quantitative data showed that participants who had been actively pre-briefed on the content of the discussion (rather than being left to browse the website independently) were able to contribute more actively to the event. 


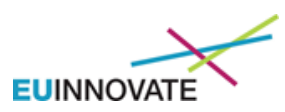

Future research into what motivates individuals to participate in crowdsourcing activities would complement this work, as would research which examines the different logics or identities which individuals identify with when they participate. The theme of education for sustainable entrepreneurship was a very significant one which would merit more in-depth research. Finally, more research on innovation within the policymaking process conducted with policymakers would be invaluable if access could be secured.

\section{REFERENCES}

Aitamurto, T. (2012). Crowdsourcing for Democracy: A new era in policy-making. Publications of the Committee for the Future, Parliament of Finland, 1.

Audretsch, D.B., Grilo, I. and Thurick, A.R. (2007). Explaining entrepreneurship and the role of policy: a framework. In: D. B. Audretsch, I. Grilo, and A. R. Thurick (eds.). Handbook Of Research On Entrepreneurship Policy. Edward Elgar, Cheltenham, pp. 18-36.

Audretsch, D.B. and Link, A.N. (2012). Entrepreneurship and innovation: Public policy frameworks. Journal of Technology Transfer. 37 (1). pp. 1-17.

Belz, F.M. and Binder, J.K. (2015). Sustainable Entrepreneurship: A Convergent Process Model. Business Strategy and the Environment, pp1-17.

Blanchet, T. (2015). Struggle over energy transition in Berlin: How do grassroots initiatives affect local energy policy-making? Energy Policy. 78. pp. 246-254.

Cajaiba-Santana, G. (2014). Social innovation: Moving the field forward. A conceptual framework. Technological Forecasting \& Social Change. 82. pp. 42-51.

Chalmers, D. (2012). Social innovation: An exploration of the barriers faced by innovating organizations in the social economy. Local Economy. 28 (1). pp. 17-34.

Chesbrough, H. (2012). Open Innovation: Where We've Been and Where We're Going. Research-Technology Management. 55 (4). pp. 20-27.

Denise Threlfall, K. (1999). Using focus groups as a consumer research tool. Journal of Marketing Practice: Applied Marketing Science. 5 (4). pp. 102-105.

Devinney, T.M., Auger, P. and Eckhart, G.M. (2010). The Myth of the Ethical Consumer. Cambridge University Press, New York.

Elzen, B., Geels, F.W., Leeuwis, C. and Van Mierlo, B. (2011). Normative contestation in transitions 'in the making': Animal welfare concerns and system innovation in pig husbandry. Research Policy. 40 (2). pp. 263-275.

Estelles-Arolas, E. and Gonzales-Ladron-de-Guevara, F. (2012). Towards an integrated crowdsourcing definition. Journal of Information Science. pp. 1-22.

European Commission (1996). Green Paper on innovation. Document drawn up on the basis of COM(95) 688 final, Bulletin of the European Union Supplement 5/95

Foxon, T. and Pearson, P. (2008). Overcoming barriers to innovation and diffusion of cleaner technologies: Some features of a sustainable innovation policy regime. Journal of Cleaner Production. 16 (1). pp. 148-161.

Garuda, R. and Karnøe, P. (2003). Bricolage versus breakthrough: distributed and embedded agency in technology entrepreneurship. Research Policy. 32 (2). pp. 277-300.

Geels, F.W. (2002). Technological transitions as evolutionary reconfiguration processes: a multi- 
level perspective and a case-study. Research Policy. 31 (8-9). pp. 1257-1274.

Geels, F.W. (2011). The multi-level perspective on sustainability transitions: Responses to seven criticisms. Environmental Innovation and Societal Transitions. 1 (1). pp. 24-40.

Geels, F.W. (2010). Ontologies, socio-technical transitions (to sustainability), and the multi-level perspective. Research Policy. 39 (4). pp. 495-510.

Geels, F.W. (2004). From sectoral systems of innovation to socio-technical systems: Insights about dynamics and change from sociology and institutional theory. Research Policy. 33 (67). pp. 897-920.

Geels, F.W. and Schot, J. (2007). Typology of sociotechnical transition pathways. Research Policy. 36 (3). pp. 399-417.

Gouldson, A., Lopez-Gunn, E., Van Alstine, J., Rees, Y., Davies, M. and Krishnarayan, V. (2008). New alternative and complementary environmental policy instruments and the implementation of the Water Framework Directive. European Environment. 18 (August). pp. 359-370.

Granovetter, M.S. (1973). The Strength of Weak Ties. The American Journal of Sociology. pp.1360-1380.

Greenbaum, T.L. (1998). The Handbook for Focus Group Research. Sage Publications, Thousand Oaks.

Gunningham, N. and Sinclair, D. (1999). Regulatory pluralism: Designing policy mixes for environmental protection. Law \& Policy, 21(1), pp.49-76.

Henkel, J. and von Hippel, E. (2005). Welfare Implications of User Innovation. Journal of Technology Transfer. 30 (1-2). pp. 73-87.

von Hippel, E. (2005). Democratizing Innovation. MIT Press, Cambridge (MA).

Hockerts, K. and Wüstenhagen, R. (2010). Greening Goliaths versus emerging Davids Theorizing about the role of incumbents and new entrants in sustainable entrepreneurship. Journal of Business Venturing. 25 (5). pp. 481-492.

Jackson, T. and Michaelis, L. (2003). Policies for Sustainable Consumption. Sustainable Development Commission, London.

Konisky, D.M. and Beierle, T.C. (2001). Innovations in Public Participation and Environmental Decision Making: Examples from the Great Lakes Region. Society \& Natural Resources. 14 (August). pp. 815-826.

Koontz, T.M.. (2006). Collaboration for sustainability? A framework for analyzing government impacts in collaborative-environmental management. Sustainability: Science, Practice, \& Policy. 2 (1). pp. 15-24.

Kozinets, R. V. (2002). The Field Behind the Screen: Using Netnography for Marketing Research in Online Communities. Journal of Marketing Research. 39 (1). pp. 61-72.

Lee, S.M., Hwang, T., Choi, D. and Authors, F. (2012). Open innovation in the public sector of leading countries. Management Decision. 50 (1). pp. 147-162.

Lettice, F. and Parekh, M. (2010). The social innovation process: themes, challenges and implications for practice. International Journal of Technology Management. 51 (1). p. 139.

Martins, T.C.M. and Bermejo, P.H.D.S. (2015). Open social innovation. In: Economics: Concepts, Methodologies, Tools and Applications. IGI Global, Pennsylvania, pp. 361-380.

Mergel, I. and Desouza, K. (2013). Implementing Open Innovation in the Public Sector: The Case of Challenge. gov. Public Administration Review. 73 (December). pp. 882-890.

Mont, O., Neuvonen, A. and Lähteenoja, S. (2014). Sustainable lifestyles 2050: stakeholder visions, emerging practices and future research. Journal of Cleaner Production. 63. pp. 24- 
32.

Nielsen, K.R., Reisch, L. a. and Thøgersen, J. (2016). Sustainable user innovation from a policy perspective: a systematic literature review. Journal of Cleaner Production. 133. pp. 65-77.

Nykvist, B. and Whitmarsh, L. (2008). A multi-level analysis of sustainable mobility transitions: Niche development in the UK and Sweden. Technological Forecasting and Social Change. 75 (9). pp. 1373-1387.

Ölander, F. and Thøgersen, J. (1995). Understanding of consumer behaviour as a prerequisite for environmental protection. Journal of Consumer Policy. 18 (4). pp. 345-385.

Persson, ̊. (2006). Characterizing the policy instrument mixes for municipal waste in Sweden and England. European Environment. 16. pp. 213-231.

Poetz, M.K. and Schreier, M. (2012). The value of crowdsourcing: Can users really compete with professionals in generating new product ideas? Journal of Product Innovation Management. 29 (2). pp. 245-256.

Rennings, K. (2000). Redefining innovation - eco-innovation research and the contribution from ecological economics. Ecological Economics. 32 (2). pp. 319-332.

Rip, A. and Kemp, R. (1998). Technological change. In: S. Rayner and E. L. Malone (eds.). Human Choice and Climate Change. Battelle Press, Columbus, OH, pp. 327-399.

Seyfang, G. and Smith, A. (2007). Grassroots innovations for sustainable development: Towards a new research and policy agenda. Environmental Politics. 16 (4). pp. 584-603.

Smith, A., Voß, J.-P. and Grin, J. (2010). Innovation studies and sustainability transitions: The allure of the multi-level perspective and its challenges. Research Policy. 39 (4). pp. 435-448.

Taylor, C., Pollard, S., Rocks, S. and Angus, A. (2012). Selecting Policy Instruments for Better Environmental Regulation: A Critique and Future Research Agenda. Environmental Policy and Governance. 22 (4). pp. 268-292.

Taylor, C.M., Lockhart-Mummery, E., Pollard, S.J.T., Angus, a J. and Allen, C. (2013a). 20 ways to influence business behaviour - A short guide to instrument selection for policy makers and regulators. Working paper, Cranfield University, UK.

Taylor, C.M., Pollard, S.J.T., Angus, A.J. and Rocks, S. a. (2013b). Better by design: Rethinking interventions for better environmental regulation. Science of the Total Environment. 447. pp. 488-499.

Thøgersen, J. (2005). Consumer behaviour and the environment: Which role for information? In: S. Krarup and C. S. Russel (eds.). Environment, information and consumer behaviour. Edward Elgar Publishing, Cheltenham, UK, pp. 51-63.

Unruh, G.C. (2000). Understanding carbon lock-in. Energy Policy. 28 (12). pp. 817-830.

Verbong, G. and Geels, F. (2007). The ongoing energy transition: Lessons from a sociotechnical, multi-level analysis of the Dutch electricity system (1960-2004). Energy Policy. 35 (2). pp. 1025-1037.

West, J., Salter, A., Vanhaverbeke, W. and Chesbrough, H. (2014). Open innovation: The next decade. Research Policy. 43 (5). pp. 805-811. 
EUINNOVATE

Table 1. Method for crowdsourcing policy for sustainable entrepreneurship

\begin{tabular}{cl}
\hline 1. DESIGN & Identification of policy areas \\
1.1 & Selection of the online platform and design of the online event \\
1.2 & Preparation of moderators \\
1.3 & Identifying and briefing guest contributors \\
1.4 & Recruiting participants \\
1.5 & \\
& \\
\hline 2. IMPLEMENTATION \\
3.1 & Coding of barriers and enablers to sustainable entrepreneurship \\
3.2 & Coding of policy measures for sustainable entrepreneurship \\
3.3 & Second coding of policy measures \\
3.4 & Categorization of policies \\
& Validation of findings with members of the crowd \\
\hline
\end{tabular}


Table 2. Sample profile

Pre-study participants: workshops \& interviews ${ }^{13}$

\begin{tabular}{lcc}
\hline Roles & Participants (number) & Participants (percentage) \\
Academic & 39 & $43.8 \%$ \\
Policymaker & 25 & $28.1 \%$ \\
Business person / & 15 & $16.9 \%$ \\
$\quad$ Entrepreneur & & \\
Thought leader / NGO & 10 & $11.2 \%$ \\
Total participants & $\mathbf{8 9}$ & \\
\hline
\end{tabular}

Crowdsourcing participants: Sustainability Innovation Exchange online conference

\begin{tabular}{|c|c|c|}
\hline Number of roles & Participants (number) & Participants (percentage) \\
\hline 5 or more & 19 & $12.6 \%$ \\
\hline 4 & 12 & $8.0 \%$ \\
\hline 3 & 24 & $16.0 \%$ \\
\hline 2 & 31 & $20.7 \%$ \\
\hline 1 & 58 & $38.6 \%$ \\
\hline 0 & 6 & $4.0 \%$ \\
\hline Roles (participant code) & Participants (number) ${ }^{14}$ & Participants (percentage) \\
\hline Business person $\quad$ (B) & 67 & $44.7 \%$ \\
\hline Academic & 65 & $43.3 \%$ \\
\hline Citizen / voter & 59 & $39.3 \%$ \\
\hline Thought-leader & 56 & $37.3 \%$ \\
\hline Entrepreneur & 39 & $26.0 \%$ \\
\hline NGO & 22 & $14.7 \%$ \\
\hline Investor & 9 & $6.0 \%$ \\
\hline Policymaker $\quad$ (PM) & 9 & $6.0 \%$ \\
\hline Public sector employee(PSE) & 8 & $5.3 \%$ \\
\hline Total participants & 150 & \\
\hline \multicolumn{3}{|c|}{ Post-study participants: validation events ${ }^{15}$} \\
\hline Academic & 48 & $52.7 \%$ \\
\hline Policymaker & 5 & $5.5 \%$ \\
\hline Thought-leader/NGO & 25 & $27.5 \%$ \\
\hline $\begin{array}{l}\text { Business person/ } \\
\text { Entrepreneur }\end{array}$ & 13 & $14.3 \%$ \\
\hline Total participants & 91 & \\
\hline
\end{tabular}

13 Pre-study events comprise three face-to-face workshops and 27 policymaker interviews. Roles were allocated by the authors based on job title and other data provided by the participants.

${ }^{14}$ Roles were selected by participants on registration to the Sustainability Innovation Exchange; multiple selections were allowed.

${ }^{15}$ Validation events comprise one round table event with policymakers and two face-to-face conferences. Roles were allocated by the authors based on job title and other data provided by the participants. 
Table 3: Enablers of and policy for sustainable entrepreneurship

\begin{tabular}{lll}
\hline Enablers of sustainable entrepreneurship & Policy domain & Policy focus: example policy measures
\end{tabular}

Motivation: Change educational logics - Role models and mentors - Emotional resilience - Visibility of impact - Persistence to engage

Ability: Change educational Logics - Project management skills - Organization skills - Creativity and reflexivity - Personal development

Opportunity: Change educational logics - Resilience to failure - Behavioral tools (i.e. nudging) Engagement with incumbent actors
Encouraging experience-based learning:

Support exchange and volunteering schemes

\section{Support mentoring schemes \\ Creating \\ awareness \\ Changing learning-based education:}

\& skills

Embed sustainability and innovation in curricula

Deliver informal sustainability education
Motivation: Role models and mentors - Emotional resilience - Reducing fear of others - Personal success story - Culture of engagement

Ability: Project management skills - Organization skills Access to money, time, and mobility - Ability to engage - Resilience to failure

Opportunity: Role models and mentors - Formal networking opportunities - Informal networking opportunities - Availability of resources - Joined-up government
Creating and maintaining knowledge networks:

Create and maintain database of ideas

Establish and promote portals for sharing stories

Provide sharing platforms and one-stop shops

\section{Identifying new ideas:}

Conduct crowdsourcing and open innovation

Support development and sharing of IP

Utilize formal networks and hubs

Utilize informal networks

Leveraging knowledge through collaboration:

Leverage formal network and hubs

Leverage Informal networks

Facilitate collaborations

Create network of networks
Motivation: Resilience (e.g. early stage risk) - Funds for experimental ideas - Appeals to non-financial motivation - Trust -Willingness to forego immediate gains

Ability: Measuring multiple impact domains - Show environmental and social impact risks - Project management skills - Organization skills

Opportunity: Formal opportunities - Availability of resources - Sustainable Entrepreneur Status - Longterm investment strategies - Joined-up government
Governing sustainable investment:

Reform financial system

Fund green investment vehicles

Reorient pension fund investment

Funding Prioritizing funding flows:

\&

Incentivize corporate venturing

Facilitate (and contribute to) crowdfunding

Provide loan guarantees

Establishing a legal form for sustainable ventures 
cont...

Motivation: Motivating change - Peer pressure

Ability: Integrating impact - Marketability of impacts -

Change-making language - Access to resources, competences and time

Opportunity: Availability of resources - Stakeholder involvement in measuring impact - Access to impact measurement tools - Joined-up government

Motivation: Success stories - Culture of engagement Resilience (e.g. motivation to try new things)

Ability: Resource buffers - Adaptive policies

Opportunity: Availability of resources - Behavioural tools (i.e. nudging) - Experimentation and pilot-testing Stakeholder involvement - Joined-up government Open innovation with government - Transparency in policymaking
Policy domain

Policy focus: example policy measures

Setting vision and direction:

Provide "flexible certainty"

Promote measures as a management tool

Scoping impact:

Develop comparable measures

Incorporate stakeholder perspectives

Emphasize regenerative measures

\section{Measuring Accounting for complexity:}

impact Consider unintended consequences

Measure what might become

Recognize interconnectedness of impacts

performance

Developing better models:

Use models to evaluate impact

Forecast macro impact of niche innovation

Using measurement and communication of impact to drive behavior:

Incentivize impact investors

Communicate impactful stories

Reward positive impact (prizes and awards)

Innovating the policymaking process:

Encourage risk taking and innovation

Involve stakeholders in policy development

Expand policy repertoire

Decouple policy from political cycles

Removing policy barriers:

Reduce bureaucracy

Innovating

Confer trust in market forces

Encourage self-regulation

Maintaining existing policy approaches:

Internalize externalities

Incentivize eco-efficient behavior of businesses and individuals

Base purchasing decisions on sustainability criteria

Supporting sustainable entrepreneurship:

Recognize aggregate impact of niche innovation

Providing a universal basic income 
Table 4: Policy recommendations classified using Taylor et al. (2013b) typology

\begin{tabular}{lll}
\hline \multicolumn{1}{c}{ Policy Type } & $\begin{array}{l}\text { No. of policy } \\
\text { recommendations }\end{array}$ & \multicolumn{1}{c}{ Examples } \\
\hline Support mechanisms and capacity building & 17 & $\begin{array}{l}\text { Use of formal and informal networks to identify new } \\
\text { ideas } \\
\text { Funding green investments }\end{array}$ \\
\hline Economic instruments & 7 & $\begin{array}{l}\text { Taxation } \\
\text { Incentivising eco-efficiency of businesses }\end{array}$ \\
\hline Co-regulations and self-regulation & 6 & $\begin{array}{l}\text { B Corp implementation } \\
\text { Review the scope of impacts }\end{array}$ \\
\hline Information based instruments & 3 & $\begin{array}{l}\text { Communication of impactful stories } \\
\text { Creating and maintaining a database of ideas }\end{array}$ \\
\hline Direct command and control regulation & 0 & None \\
\hline
\end{tabular}


EUINNOVATE

Table 5: Worked example of policy framework applied to the European Union context

\begin{tabular}{|c|c|c|}
\hline Policy domain & Policy focus & Recommendation to EU policymakers \\
\hline & $\begin{array}{l}\text { Encouraging experience-based } \\
\text { learning }\end{array}$ & $\begin{array}{l}\text { 1.Upscale sustainable entrepreneurship in Erasmus+ and Erasmus for } \\
\text { Young Entrepreneur schemes }\end{array}$ \\
\hline Creating skills \& awareness & Changing learning-based education & $\begin{array}{l}\text { 2. Align sustainability and entrepreneurship in strategic frameworks for } \\
\text { education and training (via Bologna Process negotiation for integration } \\
\text { into the European Qualifications Framework and Education \& } \\
\text { Training } 2020 \text { Strategic Framework) }\end{array}$ \\
\hline \multirow{2}{*}{ Building networks } & $\begin{array}{l}\text { Leveraging knowledge through } \\
\text { collaboration }\end{array}$ & $\begin{array}{l}\text { 3. Create a sustainable entrepreneurship Knowledge and Innovation } \\
\text { Community }\end{array}$ \\
\hline & $\begin{array}{l}\text { Creating and maintaining } \\
\text { knowledge networks }\end{array}$ & 4. Leverage the Europe Enterprise Network for better learning resources \\
\hline \multirow{3}{*}{ Funding \& investing } & Governing sustainable investment & $\begin{array}{l}\text { 5. Expand European funding for sustainable ventures (via European } \\
\text { Investment Bank and European Investment Fund instruments/schemes) }\end{array}$ \\
\hline & Prioritising funding flows & $\begin{array}{l}\text { 6. Leverage crowdfunding specifically for sustainable innovation } \\
\text { 7.Align European venture capital funding with corporate venturing for } \\
\text { sustainable enterprise }\end{array}$ \\
\hline & $\begin{array}{l}\text { Establishing legal form for } \\
\text { sustainable ventures }\end{array}$ & $\begin{array}{l}\text { 8. Recognise new legal enterprise form for sustainable ventures (could } \\
\text { formalize Benefit Corporations 'B Corp' as legal form at EU level) }\end{array}$ \\
\hline $\begin{array}{l}\text { Measuring impact \& } \\
\text { performance }\end{array}$ & Developing better models & $\begin{array}{l}\text { 9. Enhance strategic policymaking through agent based/scenario driven } \\
\text { impact modelling }\end{array}$ \\
\hline Innovating government & & $\begin{array}{l}\text { 10. Support new research to analyse user and citizen roles in innovative } \\
\text { policymaking }\end{array}$ \\
\hline
\end{tabular}




\section{Figure 1: A policy framework for sustainability entrepreneurship}

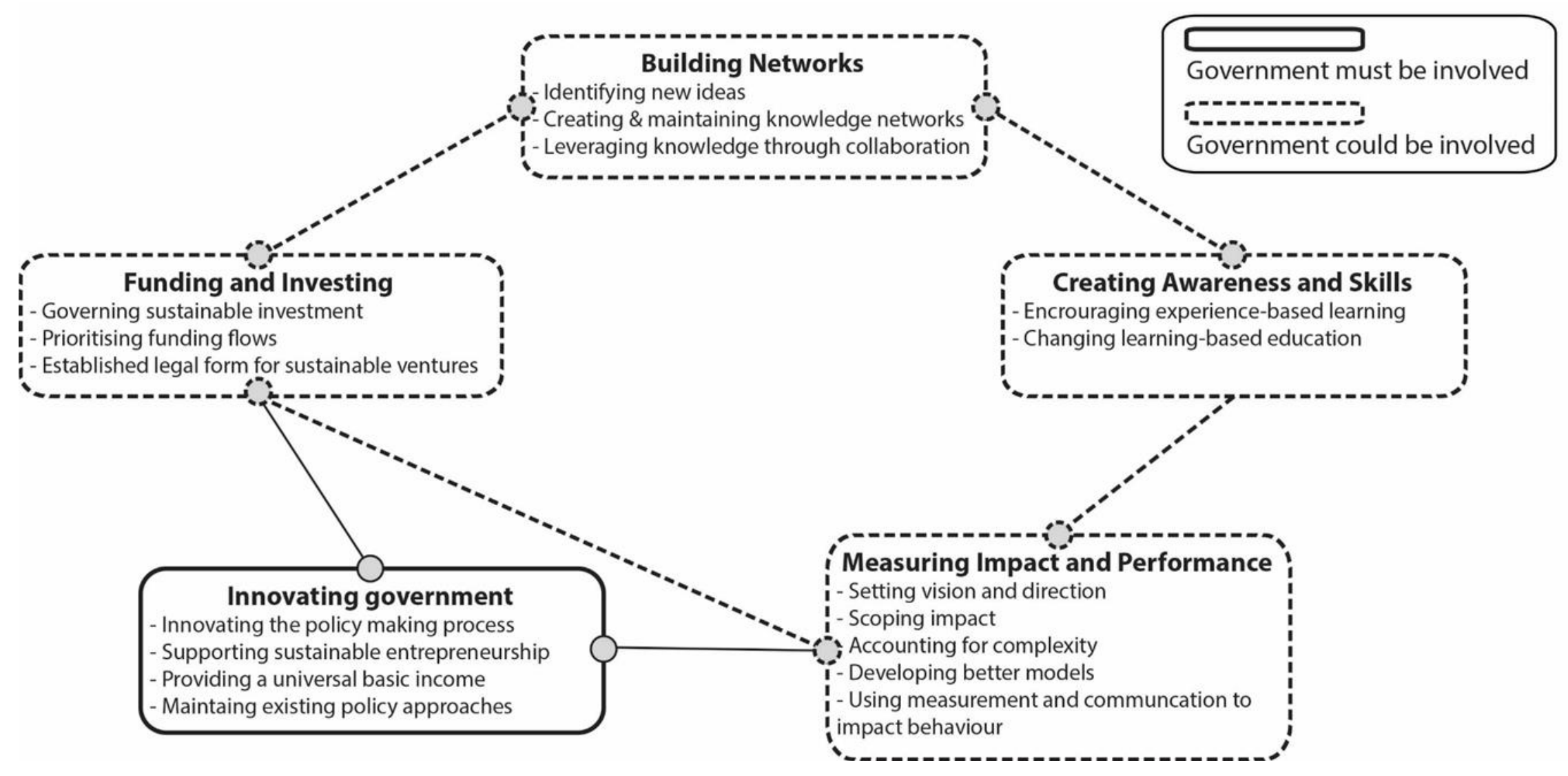


Figure 2: Selected example policies and the levels at which they are enacted

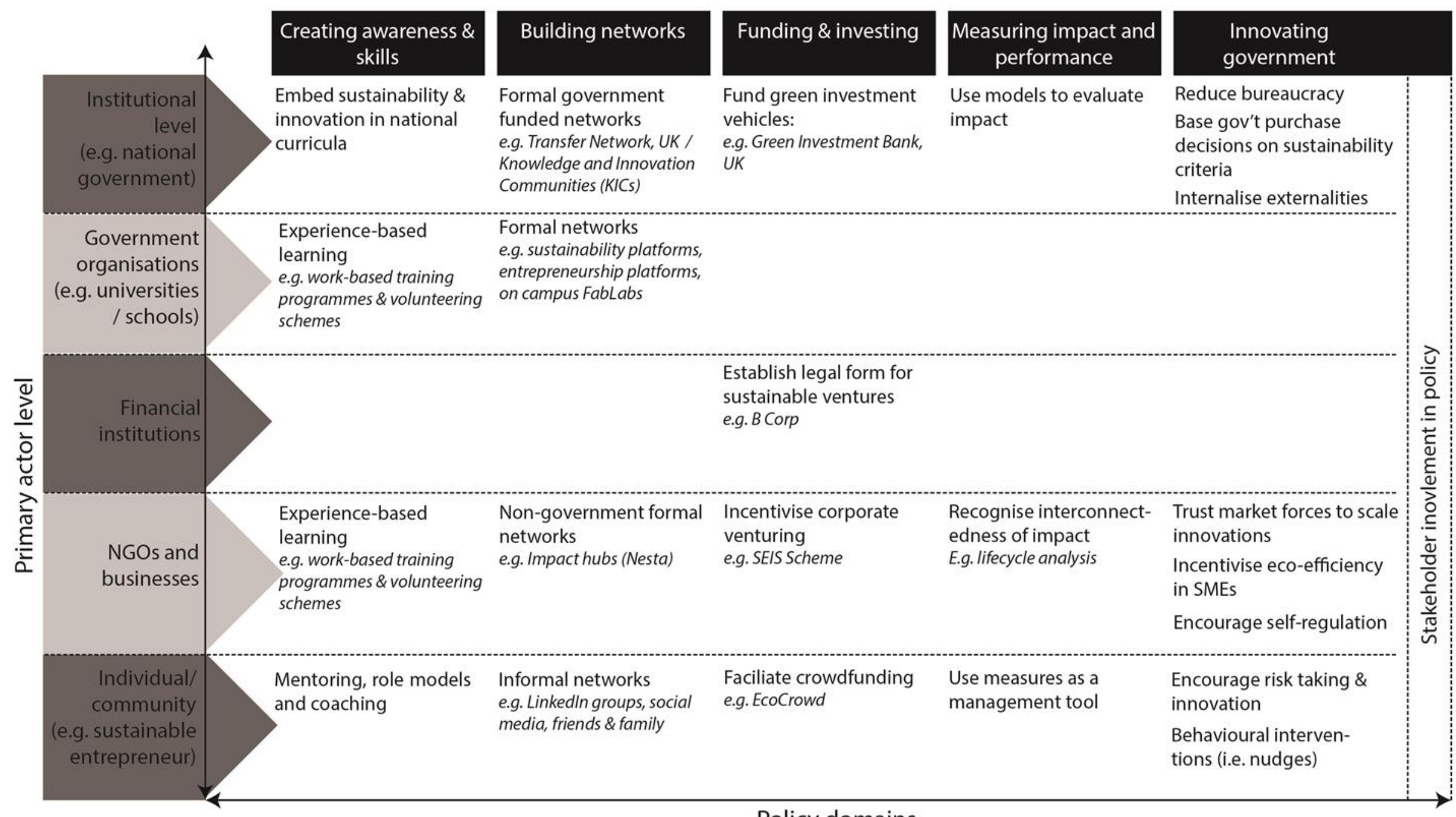

Policy domains 
EUINNOVATE

Figure 3: Adaption of the multi-level perspective to incorporate the niche enabling role of policy

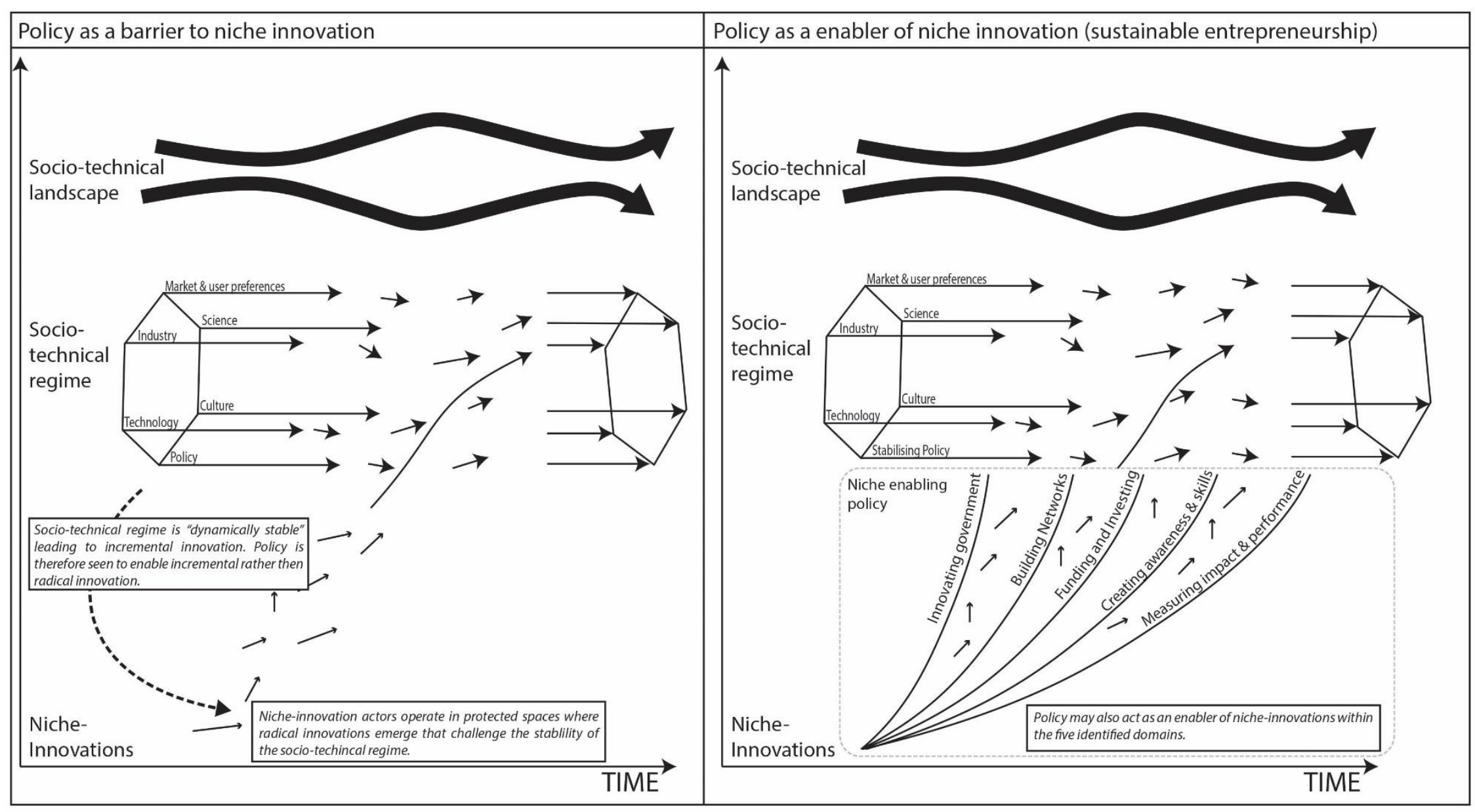




\section{Appendix 1: Summary of Audretsch et al. (2007) policy channels for entrepreneurship}

\begin{tabular}{|l|l|l|}
\hline Policy Channel & Purpose (Affects) & Examples \\
\hline G1: Demand side & $\begin{array}{l}\text { the type, number and } \\
\text { accessibility of } \\
\text { entrepreneurial opportunities }\end{array}$ & $\begin{array}{l}\text { policies stimulating technological } \\
\text { developments through subsidizing R\&D }\end{array}$ \\
\hline G2: Supply side & $\begin{array}{l}\text { the aggregate number of } \\
\text { entrepreneurs i.e. the } \\
\text { aggregate characteristics of a } \\
\text { country or society }\end{array}$ & $\begin{array}{l}\text { immigration policy, regional development } \\
\text { policy, fiscal treatment of families with children }\end{array}$ \\
\hline $\begin{array}{l}\text { G3:Abilities and } \\
\text { resource }\end{array}$ & $\begin{array}{l}\text { kelp overcome finance and } \\
\text { knowledge gaps }\end{array}$ & $\begin{array}{l}\text { development of the venture capital market, } \\
\text { direct financial support such as subsidies, grants } \\
\text { and loan guarantees, direct provision of relevant } \\
\text { 'business' information (i.e. advice and } \\
\text { counselling) or through the education system }\end{array}$ \\
\hline G4: Preferences & $\begin{array}{l}\text { Preferences toward } \\
\text { become an entrepreneur, } \\
\text { including risk attitude }\end{array}$ & $\begin{array}{l}\text { fostering entrepreneurship culture; shaping values } \\
\text { and attitudes by introducing entrepreneurial } \\
\text { elements in the education system and by paying } \\
\text { attention to entrepreneurship in the media; have to } \\
\text { assume broad concept of government policy }\end{array}$ \\
\hline $\begin{array}{l}\text { G5: Decision } \\
\text { making process }\end{array}$ & $\begin{array}{l}\text { given the right opportunities, } \\
\text { abilities, resources and } \\
\text { preferences, the individual } \\
\text { decision making process } \\
\text { evaluating the entrepreneurial } \\
\text { option versus employment or } \\
\text { unemployment }\end{array}$ & $\begin{array}{l}\text { taxation (influencing business earnings), social } \\
\text { security arrangements (willing ness to give up } \\
\text { present (un)employment to become and } \\
\text { entrepreneur), labour market legislation (affecting } \\
\text { the flexibility of the business and the } \\
\text { attractiveness of starting or continuing a business) } \\
\text { and bankruptcy policy }\end{array}$ \\
\hline $\begin{array}{l}\text { G6: Accessibility } \\
\text { of markets } \\
\text { between incumbents and } \\
\text { entrants }\end{array}$ & $\begin{array}{l}\text { competition policy and establishment } \\
\text { and bankruptcy legislation }\end{array}$ \\
\hline
\end{tabular}

